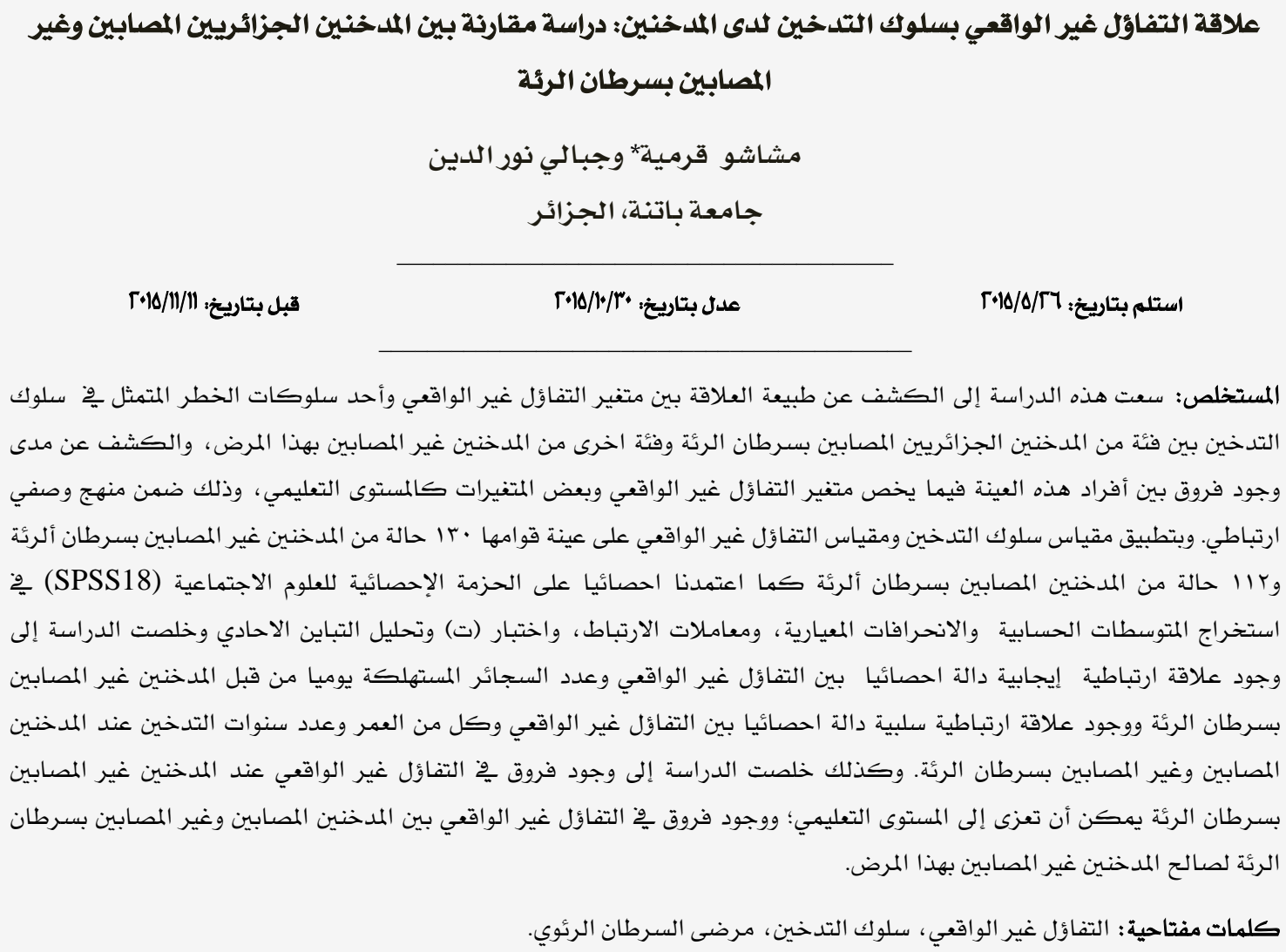

\title{
Unrealistic Optimism and its Relationship Behavior with Smoking among Smokers: Comparative Study between Algerian Smokers Affected and not Affected with Lung \\ Cancer
}

Machachou Guermia* \& Jabali Nourelddine

University of Batna, Algeria

\begin{abstract}
This study aimed to find the relationship between the unrealistic optimism and smoking. To explore the relationship, two groups: smokers with cancer and smokers with no cancer were compared. The smoking behavior scale and the unrealistic behavior scale were administered to 130 persons of smokers without lung cancer and 112 smokers who had lung cancer. The SPSS18 was used to obtain the meas, correlations, t-test and the analysis of variance. The study revealed a significant positive correlation between the unrealistic optimism and the number of daily smoked cigarettes for the smokers among non-lung cancer and a significant negative correlation between the unrealistic optimism and age and years of smoking among smokers without lung cancer. The study found a difference in unrealistic optimism among non-smokers with lung cancer due to educational level. Also, differences in unrealistic optimism between smokers infected and non-infected was found but in favor of non-infected.
\end{abstract}

Keywords: Unrealistic optimism, smoking behavior, lung cancer patients.

*machachou@yahoo.fr 
و الصحة و الدافعية للانجاز، ولنذ أصبيح التفاؤل يمثل قيمهة اجتماعية مهممة لدى معظم

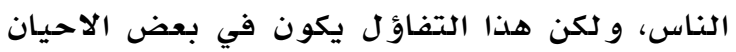
بعيدا عن الواقع وعن الظروف الحقيقية الحية للفرد مـما قد يتسبب في تفسيره الخاطئ لها يحيط بـه

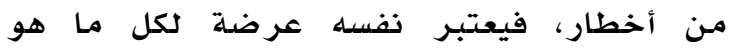
ايجابي وبعيد كل البعد عن ما هو سلبي. ان هذا

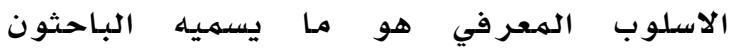

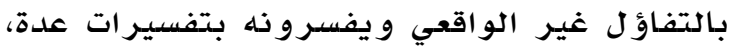

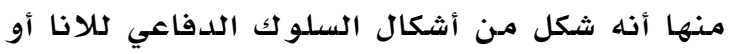

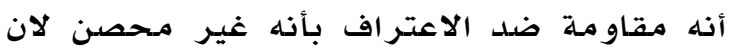
التهديد الضـار يمكن أن يولد القلق، كما فسر

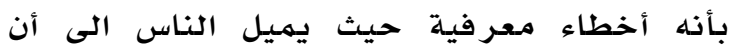
يكونوا متمرركزين حول أنفسهم و تكون لديهم صعوبة في تقبل وجهة نظر الاخرين (الانصاري،

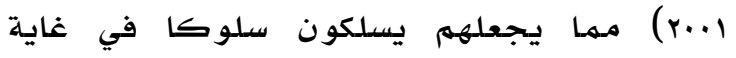
الخطورة، كسلوك التدخين وهو سلو لك حظي

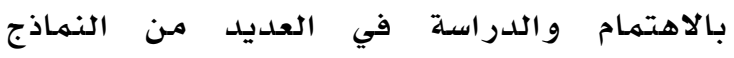
النظرية في علم نفس الصححة التي حاولت تفسير

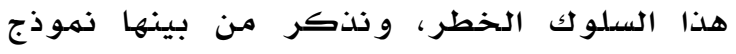
المعتقدات الصحية والذي حسبه فإن إحتمال تنفيذ الفرد لسلوكات صحية يعود مباشرة الى نتائج تقديره لخطورة المشكلات الصحية التي يواجهها، كما تتوقف مهمارسة النشاط الوقائي

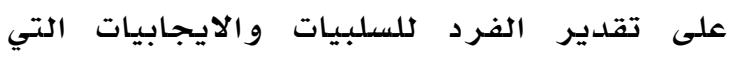

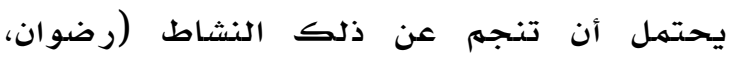

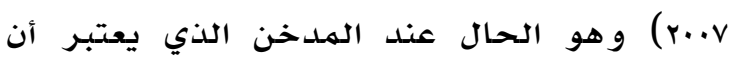
صحتله غير مهلددة وأنه بعيد عن إحتمال الاصابة

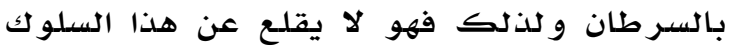

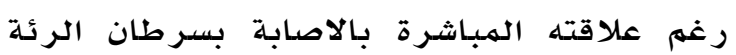
و التي أثبتتها الدراسـات الكثيرة في هذا المجال. أجرى واينستاين (Weinstein) في ·191 دراسـة على اجرئ ورئ طالبا من جامعة روتجرز في ولاية نيوجرسي الأمـريكية، إستخدم فيها مقياس أحداث

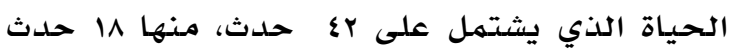
إيجابي و\& r حدث سلبي يجاب عليها بالاعتماد

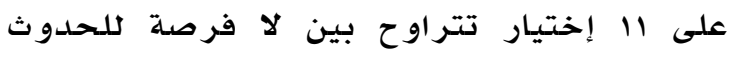

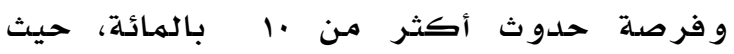

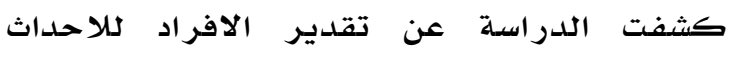
الايجابية بمعدل فوق المتوسط في حين كان
اجتهد الكثير من من العلماء والباحثين لوضع

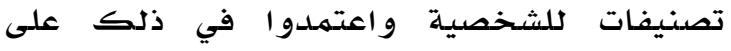
الجوانب المتعددة لها و المتمثللة في السمات التي

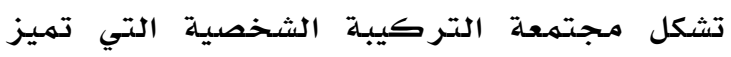

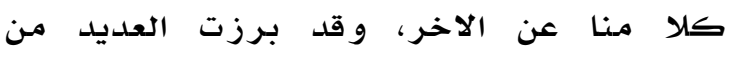

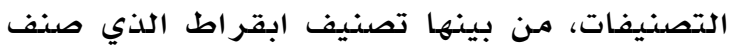

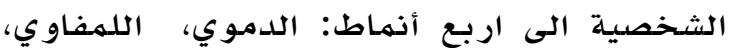

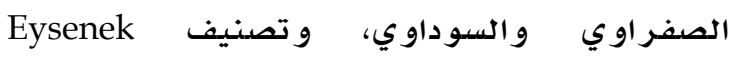

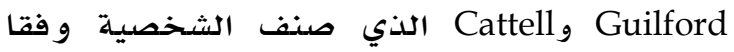

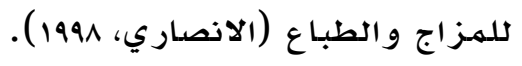

إن الملاحظ في هذه التصنيفات، هو اعتمادها

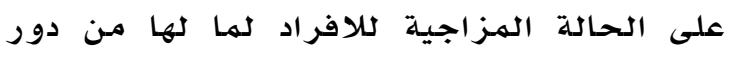

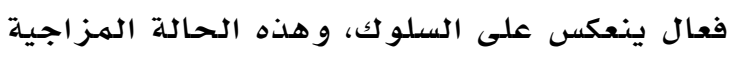
قد تفرض نفسها كسهمة قائمسة بحد ذاتها، وهو وهو

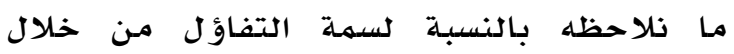

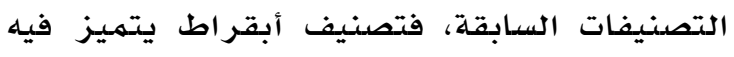

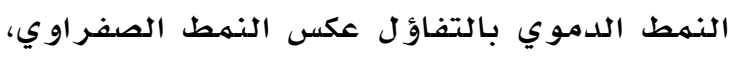
و في تصنيف Eysenek يتميز النمط الانبساطي

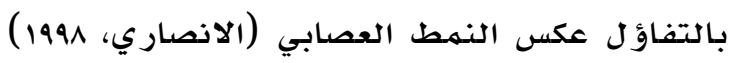

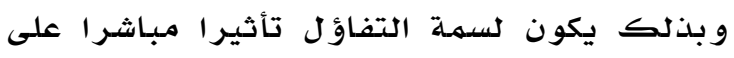
حياة الانسان وهو ما أكدته نظريات علهم النفس المختلفة، والتي نذكر منها على سبيل النها المثال

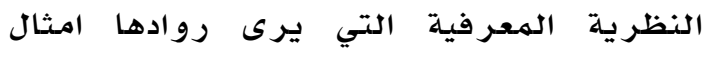
Snyder

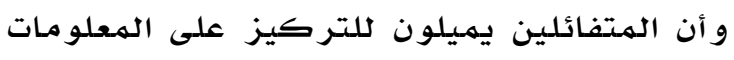

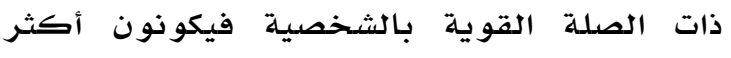

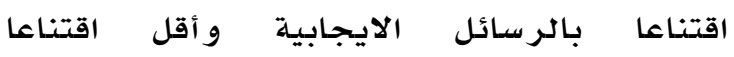

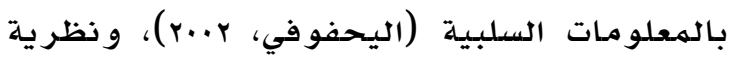

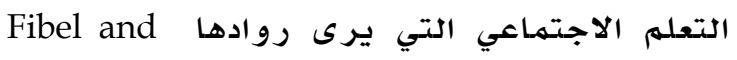

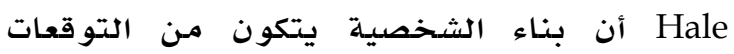
و الاهداف و الطموحات، حيث تعمل هذه الابنية بشكل تفاعلي عن طريق التعلم بالملاحظة و بناءا

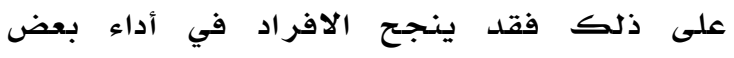

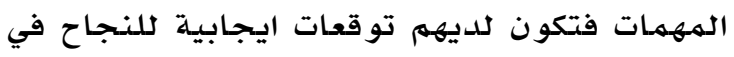
المستقبل، في حين يفشل البعض فتكون لديهم

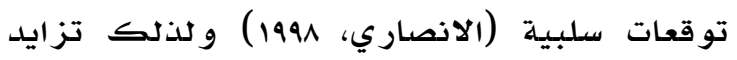

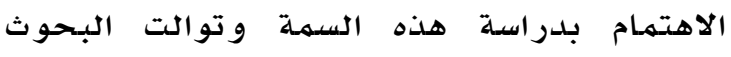
حولها في علم النفس العيادي، علم نفس الصحلة، علم نفس الشخصية و علهم النفس الاجتماعي و كلها تؤكد ارتباط هذه السمة بالسعادة 


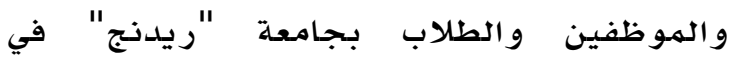

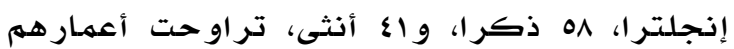

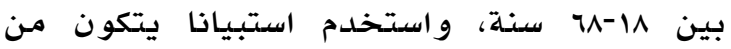
سؤالين مقارنة بالسائقين الآخرين ماهو توقيك

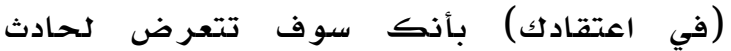
مروري أثناء قيادتك للسيارة/ مقار نة بادئة السائقين الآخرين ماهو توقيك (في اعتقادك) بأنك سوف تتعر ض لحادث مـروري عندما تكون مر افقا

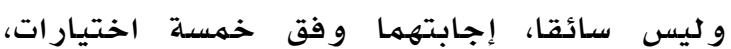
وكشفت نتائج الدراسلة عن عدم توقع السائقين

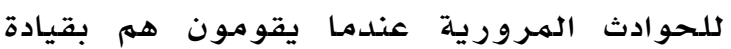
السيارة، في حين كانت توقعاتهم أكثر بالإصابة في حادث مـروري عندما يكونون مر افقين و ليسوا

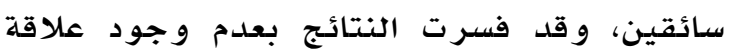
بين التفاؤل غير الواقعي وتوقع تلك الأحداث، و لكن يوجد خداع في الضبط و التحكه. F F, 1993 )

(Mekena,

دراسـة Morrisson-ager Willock 1999 دراسات اجريت عن التفاؤل غير الواقعي وطبقت

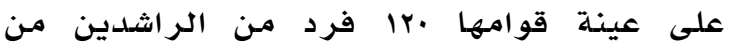
مقاطعة ملاوي في افريقيا والتي تنتشر فيها بعض الامـراض الوبائية مثل المهلاريا ، الكو ليرا و التفوئيد وقد وجه للافر اد استبيان عن احتمال اصابتهـم بتلك الامـر اضوك. وقد كشفت النتائج عن اعتقاد الفحوصين بـان

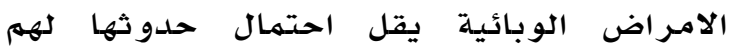

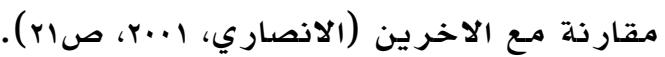
دراسة الانصاري بدر محمد 1999/1991: وهي

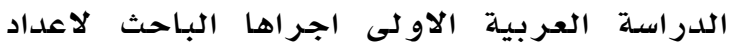
مقياس التفاؤل غير الواقعي ومن ثم ربطه ببعض سمات الشخصية وقد اعتمد على V عينات من الطلاب من جامعة الكويت.

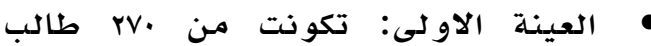
طرح عليها سؤال مفتوح بغرض برو جمـع و بناء المقياس.

العينة الثانية :تكونت من برO طالب لحساب الصدق و الثبات.

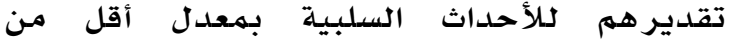
المتوسط، كها أظهرت الدراسلة تأثر التفاؤل بعوامل أخرى مثل الخبرة الذاتية و والدافعية

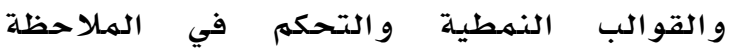

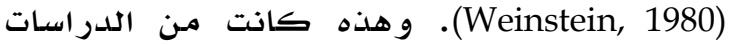
الاولى حول التفاؤل غير الواقعي، لتليها دراسات أخرى كثيرة نذكى الذور منها

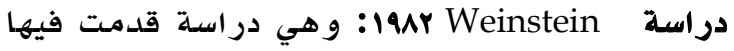
ـ ..1 طالب جامعي من الجنسين قائمة تضمر 0ـ مشكلة صحية، تشهمل عنصرين فرعيين هما

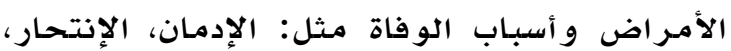

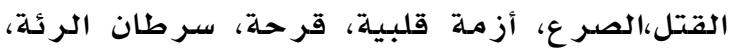

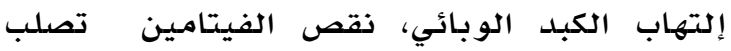

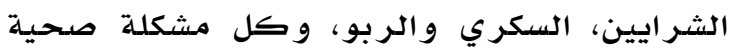
يقابلها مقياس تقدير من سبع نقاط يضم

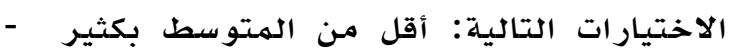
اقل من المتوسط - اقل من المتوسط بقليل -

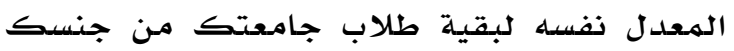

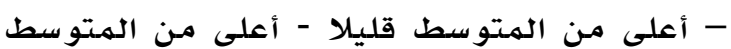

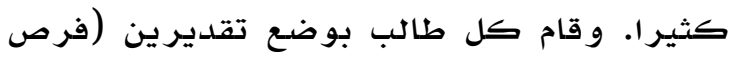

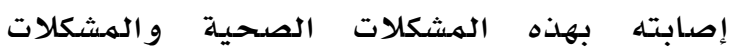

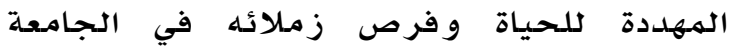
نفسها. ووكشفت نتائج الدراسلة أن للدى الطلاب تفاؤل غير واقعي (مرتفع) فقد عدوا فروصة

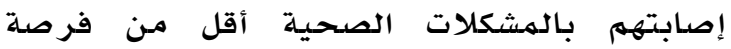

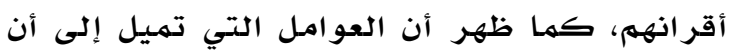
تزيد من التفاؤل غير الواقعي تتمثثل في: 1. إمكانية التحكم في المرض أو سبب الوفاة كما يدر كها الطلاب. r. - نقص الخبرة السابقة.

r. الاعتقاد أن المشكلة الصحية تظهر في وقت مبكر أي خلال الطفولة.

و بينت هذه الدراسـة أيضا أن التفاؤل غير الواقعي

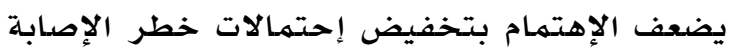

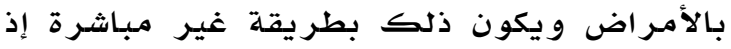

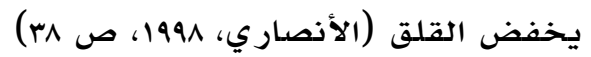
دراسة ميكانا (Mekenna, 1993): التي بلغ حجم

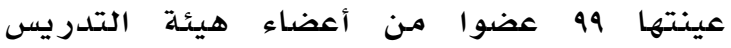


بينها سلوك التدخين واشتهل التحقيق على عينة كلية مكونة من

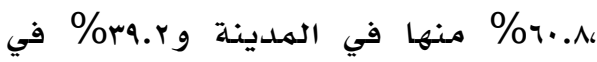

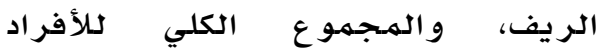

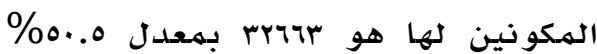

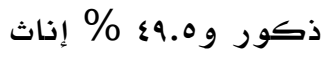

$$
\text { و توصلت النتائج الى: }
$$

\%rr.s.

$$
\text { (ذكور) }
$$

بـ. • مـن أفر اد العينـة مدخنين (إناث)

$$
\text { \% \% }
$$

ع..1

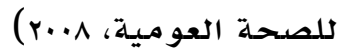

دراسـة Jal Jonathhan, Reppucci and all ووهي دراسـة أجريت على مجمهوعة مـن الهر اهقين

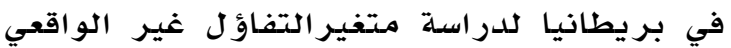
و سلو ك التدخين و تم ذلك على مـرحلتين:

المرحلة الأولى: اشتملت فيها العينة على \&ه مر اهق مدخن وع.r مر اهق غير مدخن، وبعد تطبيق استبيان حول معتقدات المراهقين حول

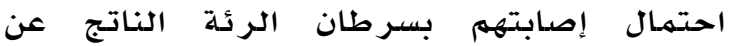
التدخين كشفت النتائج عن: إدرالك الهر اهقين غير المدخنين لفرصد إصابتهم بسرطان الرئة إدرئ بنسبة دون الهتوسط، أما الهر اهقون الهـدخنون

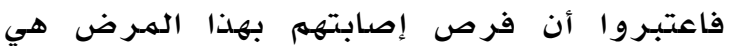
فرص عادية.

المرحلة الثانية: أو الدراسلة الثانية الهكملة

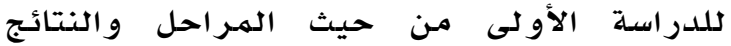

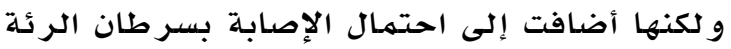

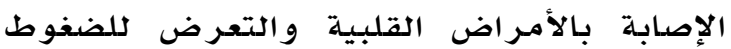
الهحتملة و والنتائج كانت: بر مراهق مدخن

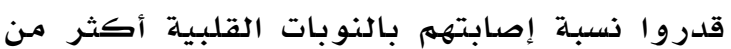

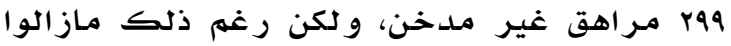

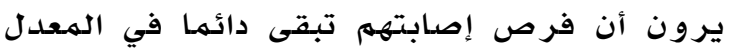

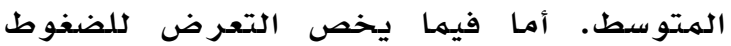

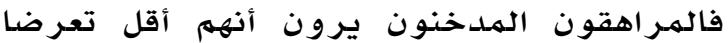

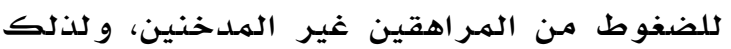

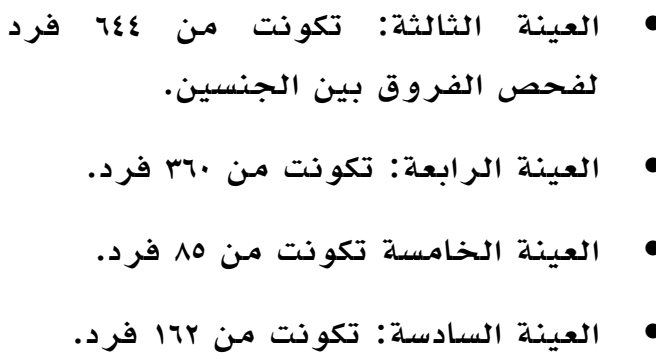
للسلوكات الههددة للصحة كسلوكات الهرات التغذية

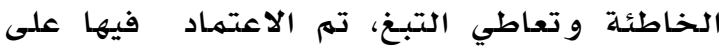
طلبة المدارس في الاردن الذين تتراوح اعمارهم

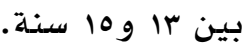
ونتائج هذه الدر اسلة كانت:

\% 19.9 من الطلبة تعاطو التبخ بكافة اشكاله لهمرة او اكثر خلال ·r يوما الاخيرة T.r. \% مـن الطلبـة دخنوا السجـائر 0.ع 7 \% من الطلبة أكدو أن اشخاصا بالغين قاموا بالتدخين بحضور هم خلادل السبعة ايام الاخيرة \% O O من الطلبة أفادوا بأن أحد الوالدين

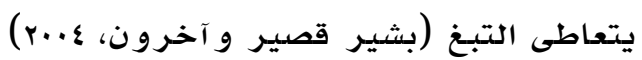
دراسـة المعهد الوطني للصحة العمهومية ه... و هي تحقيق وطني حول الصححة يندرج ضمن مشروع بحث حول علم الاوبئة والنظام الصحي ولي ولهي في دول شمال افريقيا وتمثلت اهدافه في : تقدير عدد الوفيات لدى السكان

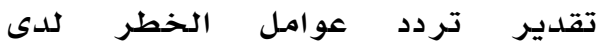

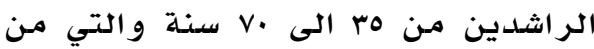




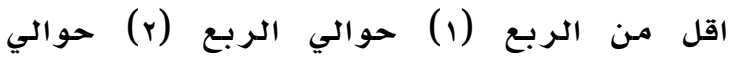

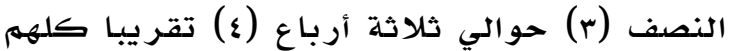

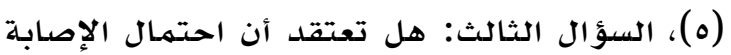

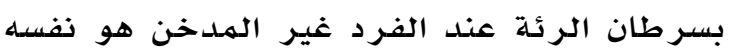
بالنسبة للفرد المدخن؟ وبدائل الإجابة هي: الهـدخن لديه إحتمال أكبر بعض الشيء مـن غير

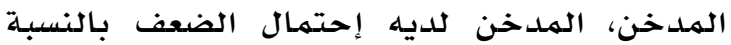

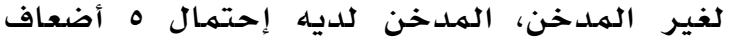

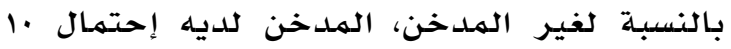
أضعاف بالنسبة لغير المدخن. ونتائج الدراسة جاءت لتؤكد الإختلاف الواضع بين المداخنين

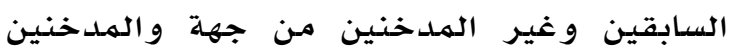
من جهة أخرى ،فيما يخص المعتقدات المتعلقة

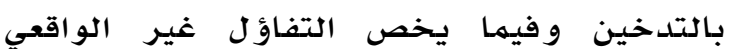
:Weinstein, Marcus and all,

التعليق على الدراسات السابقة يعكس محتوى الدرراسـات التي اطلعنـا عليها ا. معظم الدراسات التي أجريت على متغير التفاؤل غير الواقعي هي دراسات أجريت الجريت

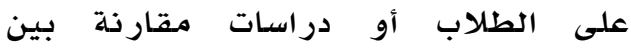
الهمر اهقين و الر اشدين.

r. استخدمت معظم الدر اسـات الاستبيان كأداة لجمـع البيانات أو لقياس التفاؤل غير الو اقعي. - ماتع

r. الدراسات السـابقة بحثت في العلاقة بين التفاؤل غير الواقعي والتعرض للمشاكل لـاكل

الصحية.

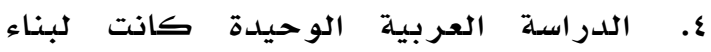
مقياس التفاؤل غير الواقعي.

\section{مشكلة البحث}

تستحوذ دراسـة سهمة التفاؤل على اهتمـام بالتغ من قبل الباحثين بوصفها خلفية عامـة تحيط بالحالة

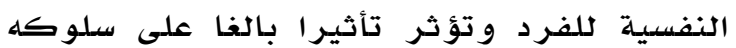
و توقعاته بالنسبـة للحاضر و المستقبل و لها تأثير

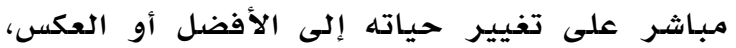

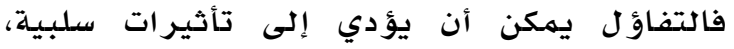
ويتضح ذلك من خلال المعالجات النظرية التي
اعتبر خداع الذات سببا للتفاؤل غير الواقعي .(Jonathan et al., 1991)

در اسـة 1990 Strecher, Kreuter and Kobrin: ورهي دراسـة أجريت بهدف التعرف على مدى وجود التفاؤل غير الواقعي لدى المدلى لدرنين للسجائر

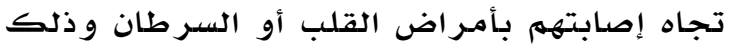

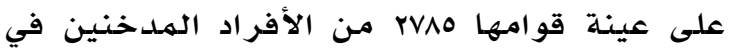

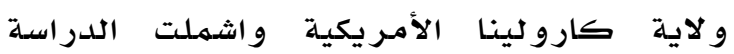

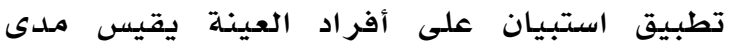

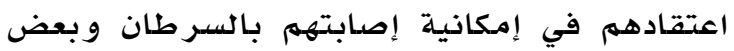

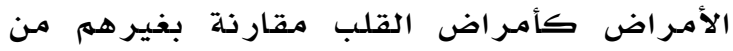
غير الهدخنين. ووكشفت النتائج انه على الرغم اهرم

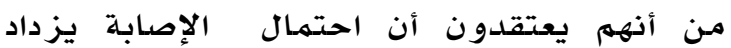

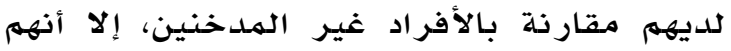

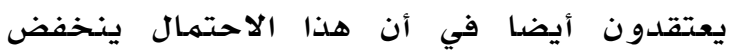

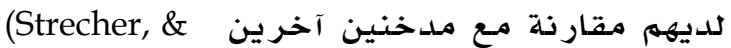
all , 1995)

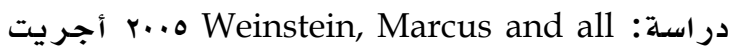
هذه الدراسلة عبر خط هاتفي يشرف عليه العديد

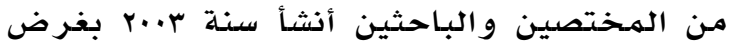

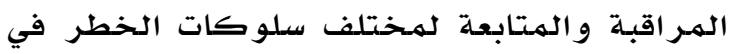
الو. م. أ وقد شملت العينة المختارة في هذه

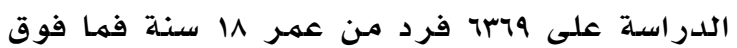
مـن مختلف الجنسيات (أفارقة، أمريكيين، إسبان) وهم يتوزعون على أربع فئات :مدخنون حاليون

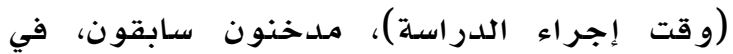
بعض الأحيان و غير مدخنين. وكان هدف هذه الدراسة معرفة العلاقة بين التفاؤل غير الواقعي والتدخين وقد طرح من أجل ذلك ثلاثة أسئلة على أفراد العينة: السؤال الأول: في اعتقادك كهم هو عدد السجائر التي يتهم تدخينها والتي يمكن أن تؤدي إلى هولى الإصابة

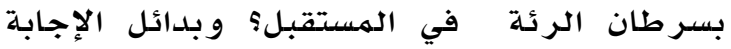

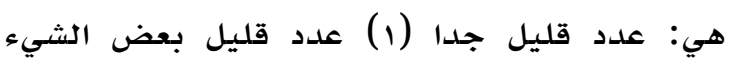

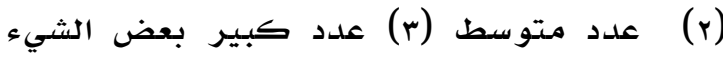

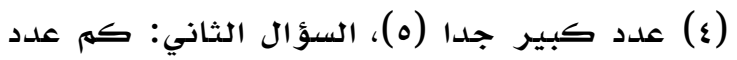
الذين تعتقد أنهم استطاعوا الشفاء مـن سرطان الرئة ؟ و بدائل الإجابة هي: 
يحتهل أن تكون فعالة في تغلبنا على أمور حياتنا اليومية، وذلك بأن لا نفكر باستمرار في لئ الأخطار المهكنة وربها تفيدنا النزعة ودة التفاؤلية عند الإنجاز قصير الأمد لكلأنشطة الروتينية، إلا الا

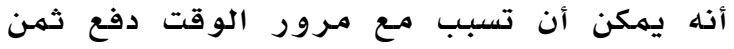

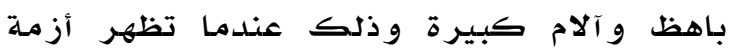
حياة كان يمكن الوقاية منها، وهذه الأزمهة يمكن

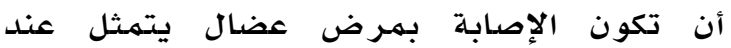
المدلدخين في مر ض سر طان الرئة الذي اكتشفت

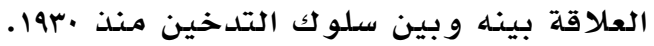

و مـع ذلك فمستهلكي السجائر والهصدابين بسرطان الرئة في تزايد، ما يدفع لطرح الكثير

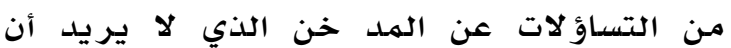

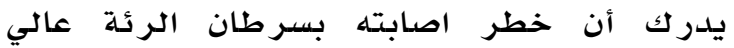
بنفس درجة المدلدنين الاخر ين:

• هل يكون خاضع لتشوه معرفي يسمى التفاؤل غير الواقعيء

• وهل الإصابة بالسرطان تؤدي إلى انخفاض هذا التفاؤل ون

وهذا يعني: هل توجد علاقة ارتباطيه دالة إحصائيا بين سلوك التدخين و والتفاؤل غير فير الواقعي عند المداخنين المصابين وغير المصدابين بسر طان الرئه؟

فر ضيات الدراسة

الفر ضية العامة

توجد علاقة ارتباطية إيجابية دالة إحصائيا بين

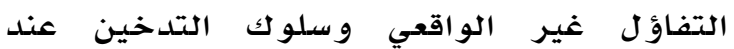
المدخنين المصدابين و غير المصدابين بسرطان

\section{الفرضيات الجزئية}

ا. توجد علاقة ارتباطية إيجابية دالة

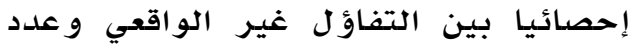
السجائر المستهلكة يوميا عند الملدخنين غير المصابين بسرطان الرئة. r. توجد علاقة ارتباطية سلبية دالة إحصائيا

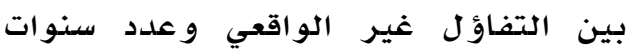

توصلت إلى أن القابلية للإصدابة بالهـرض كما يدركها الفرد تعتبر منبئا لطائفة عريضة من الن

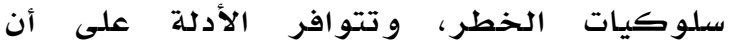
الاعتقادات المتعلقة بالحصانة الشخصية أي: عدمات القابلية لإِصابة بالأمر اض تعد خاطئة في معظم

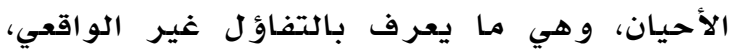
و الذي يعد نهطا من أنهاط التفاؤل قدمه لهـي (Weinstein, 1980). و وعرفه بأنه اعتقاد الناس بأن أنهاول الحوادث السلبيية يقل احتهال حلدوثها لهم

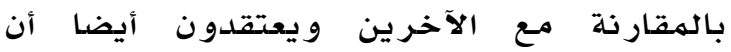

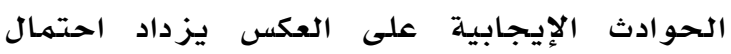

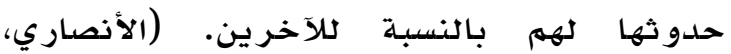
. (r..)

و هو ما قد يتسبب في التعرض لهخاطر عدة

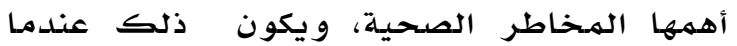
يسلك الفرد سلوكا خطرا دون الأخذ بعين الاعتبار ما يمكن أن يتر تب عنه من مضدار صحية،

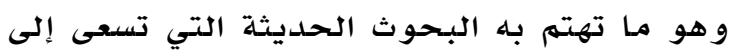

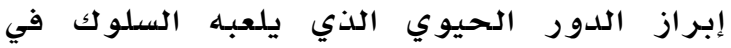

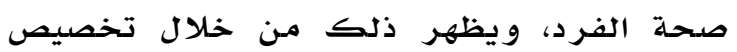
العلماء والأطباء لفرع جلديد يعرف باسهم علهم

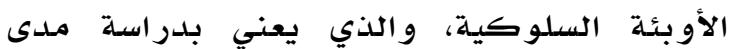
مساهمة بعض سلوكيات الخطر كالتدخين في

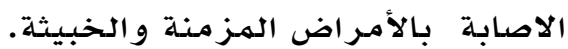

و يعتبر سلو ك التدخين من أبرز سلوكيات الخطر التي يقدم عليها الأفر اد و أكثرها انتشارا

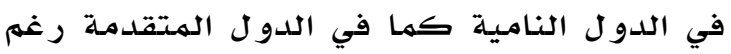

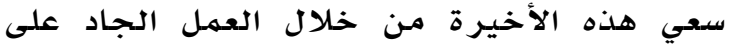

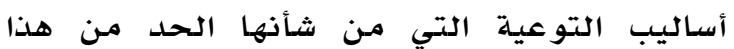

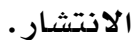

إن هذا الانتشار الواسع عشير إلى عدم الوعي

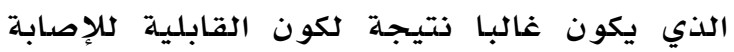

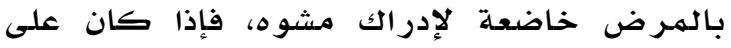

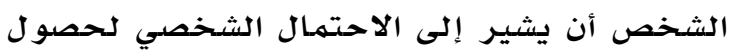
خطر مـا فإنه يقلل من أهمية هذا الخطر وذذانك لاعتقاده أنه أقل قابلية لإِصابة من من الآخرين،

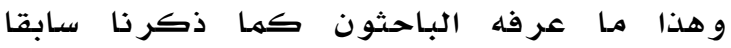
بالتفاؤل غير الواقعي وهو في الحقيقة أسلوب

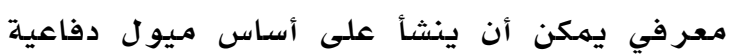




\section{أهمية الدراسة}

تكتسب الدراسة الحالية أهمية نظرية وأخرى

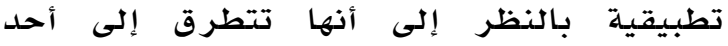

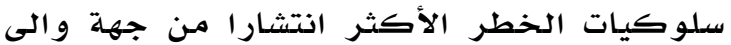

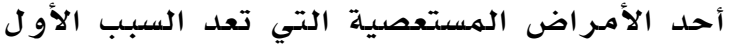

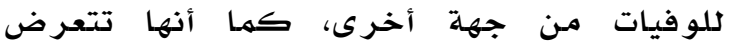

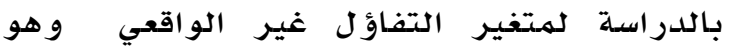
متغير رغم وجود العديد من الدراسات الأجنبية

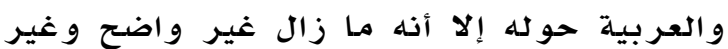

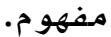

الأهمية النظرية: مجال علم نفس الصحة مجال حديث العهد نسبيا و المهلاحظ أن البحوث الحديثة البرال تسعى الى ابراز متغيرات جديدة في هذا المجال ومن ثم احاطتها بالدراسة والتحليل والتير التفسير

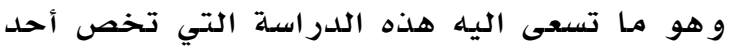

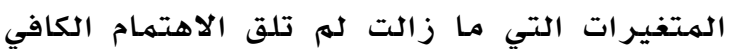

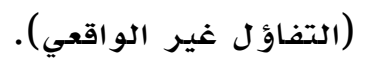

الأهمية التطبيقية: نتائج هذه الدراسة يمكن

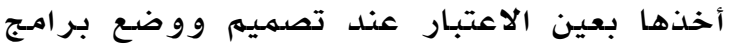
للتوعية حول أخطار سلوك التدخين من خلاد

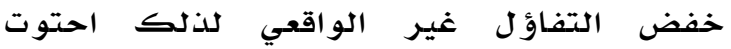

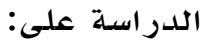

1. تصميم مقياس للتفاؤل غير الواقعي يمكن

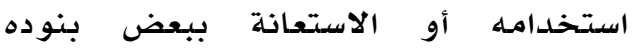
لتصميم مقاييس أخرى.

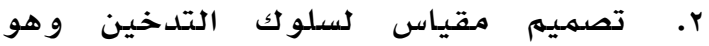
مقياس يقيس أبعاد مختلفة لهذا السلوك.

حلدود الدراسة

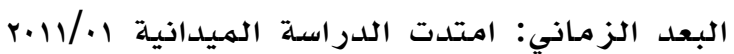

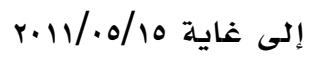

البعد المكاني: تم إجراء هذه الدراسة في كل • مدينة باتنة

مدينة الجزائر العاصمة (قسم الأمراض الصدرية التابع لمستشفى مصطفى باشا)
تدخين السجائر عند المدخنين المصابين و غير المصابين بسرطان الرئة.

r. توجد علاقة ارتباطية سلبية دالة إحصائيا

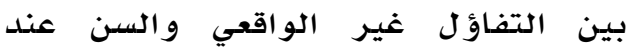
المدخنين المصابين و وغير المصابين

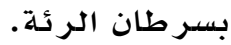
ع. توجد فروق في التفاؤل غير الواقعي عند

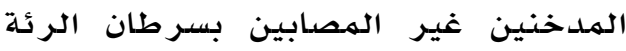
تعزى الى مستوى التعليه. ه. توجد علاقة ارتباطية ايجابية دالة إحصائيا بين التفاؤل غير الواقعي والتعود التوابية

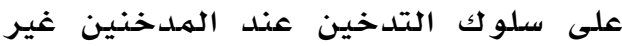
المصابين بسر طان الرئة.

1. توجد علاقة ارتباطية سلبية دالة إحصائيا بين التفاؤل غير الواقعي والوعي بأضرار

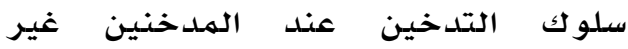
المصابين بسرطان الرئة.

V. توجد علاقة ارتباطية سلبية دالة إحصائيا

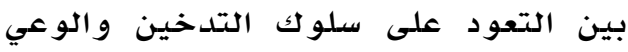
بأضراره عند المدخنين غير المصابين

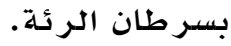
^. توجد فروق في التفاؤل غير الواقعي بين المصابين وغير المصابين بسر طان الرئة.

أهلاف الدراسة

لو تتبعنا الدراسات العربية والاجنبيـة لوجدناها قليلة جدا، لذلك هدفت هذه الدراسـة الى:

1. الكشف عن مدى و وجود التفاؤل غير

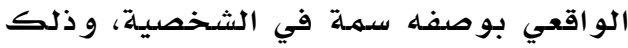
من خلال وضدع أداة لقياسـه. r. دراسة سلوك التدخين باعتباره أحد سلوكات الخطر الاكثر انتشارا واعداد العادئ أداة لقياس مختلف أبعاده. r. الكشف عن مدى ارتباط هذا السلوك

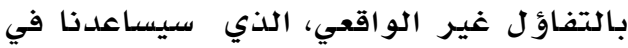

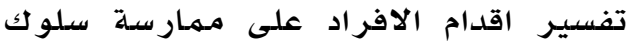
خطر يؤدي حتما الى الاضرار بصحتهم. 
كيفية تطبيقها و كلفوا بملاحظة الحالات التي تقوم بمتابعة العلاج في المستشفيات

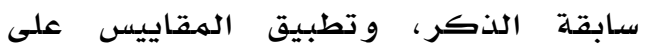
الحالات التي تسهح لها حالتها الصحية

تميزت عينة الدراسة الأسساسية بالخصائص التالية: عينة المدخنين غير المصابين بسرطان

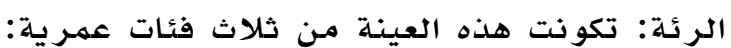

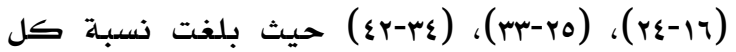

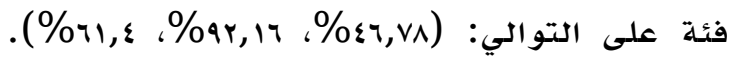
عينة المدخنين المصابين بسرطان الرئة: تكونت

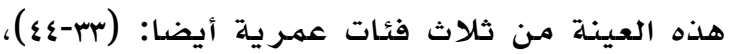

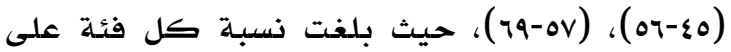

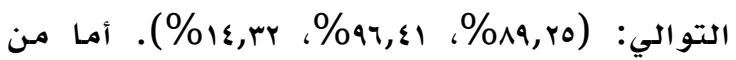

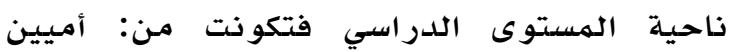

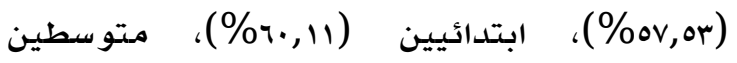

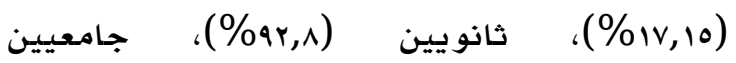
. $(\% \vee 1,1$.

\section{إجراءات الدر اسة}

تم إجر اء الدر اسـة الميدانية على مرحلتين: الدرراسة الاستطلاعية: الدراسلة

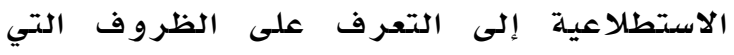

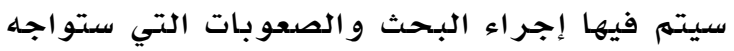
تطبيق أدوات البحث، كما تهدف إلى اختبـار مداء إدى

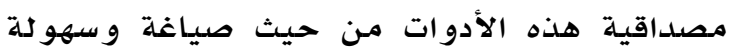
العبار ات وو ضوح التعليمات و الصدق و الثبات. الهنهج المستخدم في الدراسة الاستطلاعية: هو الهنهج الوصفي الذي يقوم على رصد و متابعة دقيقة للظاهرة أو حدث معين بطريقة كميلة أو أو نوعية في فترة زمنية معينة أو عدة فترات من فن

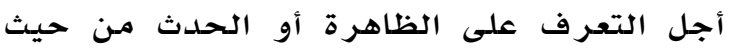

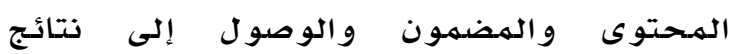
و تعميمات تسـاعد في فهم الواقع و وتطويره (ربحي، و غنيه، .... ( ر) ).

أدوات الدراسة

استخدم في هذه الدراسة مقياس التفاؤل غير الواقعي و مقياس سلو ك التدخين.

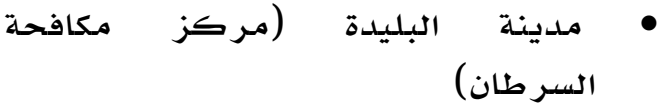

$$
\begin{aligned}
& \text { مدينة سطيف (قسم الأمـراض الصدرية }
\end{aligned}
$$

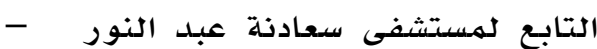

$$
\begin{aligned}
& \text { سطيف- (نتع (1) }
\end{aligned}
$$

\section{الطريقة و الإجر اءات}

عينة الدراسة

تكونت عينة الدراسة مـن بعا حالة مـن الذكور

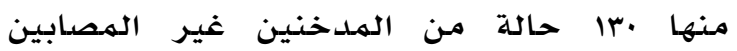

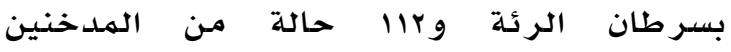
المصابين بسر طان الرئة.

ا. عينة الدراسـة الاستطلاعية:اعتمدنا في هذا

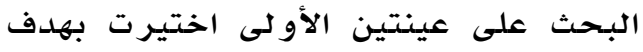
تقنين مقياس التفاؤل غير الواقعي، أما العينة الثانية فكانت متعلقة بالمتغير الثاني في البحث وهو سلوك التدخين. • العينـة الأولى: طبق مقياس التفاؤل غير

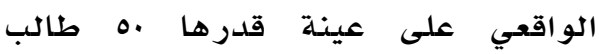

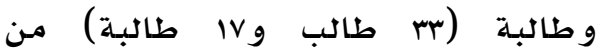

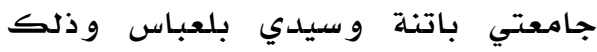
بهدف معرفة ردة الفعل اتجاه المقياس و وطبيعة التجاوب.

العينـة الثانية :تكونت العينة الثانية التي طبق عليها مقياس سلوك التدخين من فن فئ

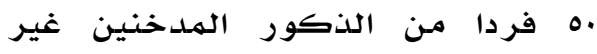

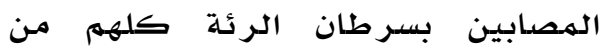
بلدية باتنـة، وقد تم اختيارهم بطريقة عرضية و تراوحت أعمارهم بين 17 إلى بلى بلى r

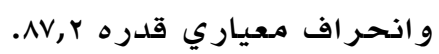

r. العينة الأساسية: تم تطبيق الدراسة على عينتين هما عينة المداخنين غير المصابين وهي العينة التي طبقت عليها الهقاييس بصورة فردية وجماعية وعينة المصابين

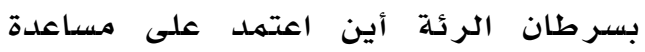

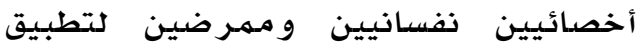
الهقاييس، بعد أن تم شرحها لهم وشرح 
مقياس Fagestrom: وهو مقياس يقيس الإدمان الفسيولوجي على مادة النيكوتين يتكون من 1 بنود لكل بند احتمالات إجابة إدابة

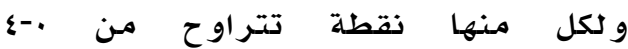
و المجمهوع الكلي يحدد درجة الإدمان، من

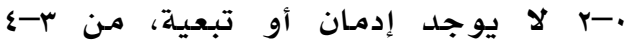
تبعية ضعيفة، من 0-1 تبعية متوسطة، من ادنان

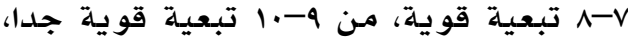

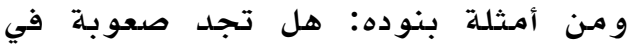
عدم التدخين في الأماكن الممنوع فئول فيها

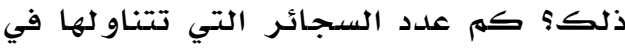
اليو م؟ (Chabrol and all, 2003)

r. مقياس سلوك التدخين (Gilliard, 2001) و هو مقياس يتكون من \ ب بند يجاب عليها

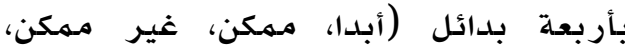
أكيد)، ومن أمثلة عبار اته: "أدخن بصورة بديرة

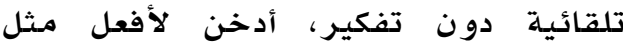

الآخرين، أدخن عندمانية أكون حزينا". (Gilliard, and Bruchon-Schweitzer, 2001)

تم تصميم المقياس بوضع البنود و تصنيفها في

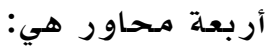

المحور الأول: بلداية تعلهم سلوك التدخين و المعتقدات الاجتماعية الداعمة لهذا السلوك. المحور الثاني: محور التعود على سلوك

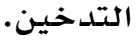

المحور الثالث: محور أسباب الاستمرار في ممارسة هذا السلوك الخطر. المحور الرابع: محور الوعي بأضرار التدخين. ويحتوي كل محور على ·1 بنود تتم الإجابة

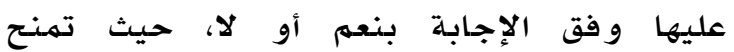

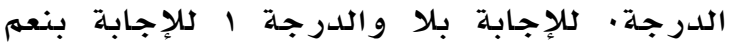

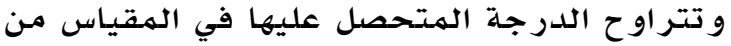

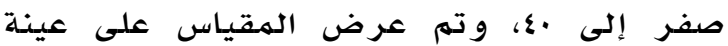
قدرها •r فردا من الذكور المداتدنين من بلدية باتنة وبلدية المعذر قصد معر فة وضوح العبار العات العات وسهو لتها، و لوحظ إجابة العينة على كل البنود و التجاو ب مع المقياس بشكل جيد.
ا. مقياس التفاؤل غير الواقعي: تم بناء هذا

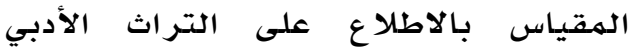

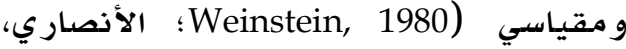
r... المقاييس التي تتناسب مـع العينة وإضافة بنود أخرى تعبر عن المتغير حتى أصبح

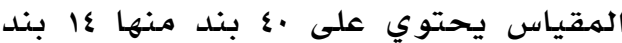

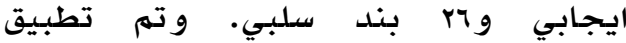
المقياس على عينة قدرها له طالب و وطالبة وتلبة من جامعتي باتنة وسيدي بلعباس بهدف معرفة ردة الفعل تجاه المقياس وطبيعة التجاوب، وتم التوصل الى حذف بندين رفض معظم الطلبة الاجابة عليها وهي الهابي (أتعرض لاعتداء مسلح، أتعرض لاعتداء

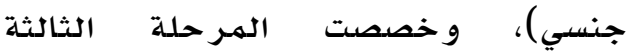
للاطلاع على رأي الأساتذة من جامعات الهرحات

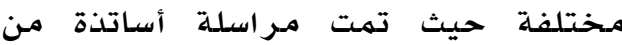
جامعة باتنة، سيدي بلعباس، الأغواط،

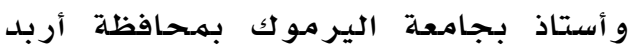

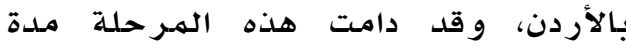

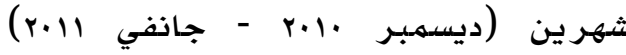
ومن خلالها تم إعادة النظر في بنود النها المقياس وحذف عدد منها ليصل المقياس

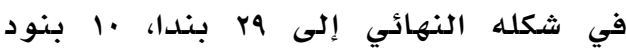

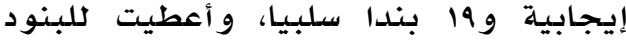

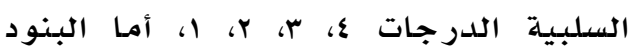

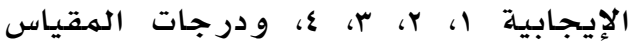

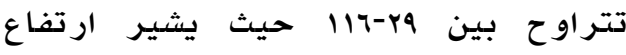
الدرجة إلى ارتفاع التفاؤل غير الواقعي. r. مقياس سلوك التدخين: تم تصميم مقياس سلوك التدخين نظرا لأن معظم المقاييس تصاس تصاسياس

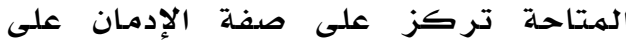
النيكوتين و تليها أهمية كبيرة، بحيث الإدان

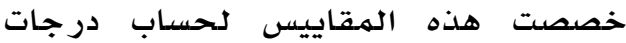
الإدمان وهو ما أدى الى الاعتماد على بعض الكض

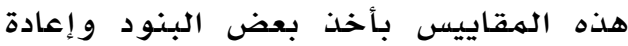
صياغة بعضها وصياغة بنود جديدة تقيس الأسل الأبعاد التي يهدف إليها البحث. 
جدول 1

صدق الاتساق الداخلي لمقياس التفاؤل غير الواقعي

\begin{tabular}{|c|c|c|c|}
\hline الدلالة & الارتباط & 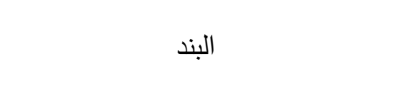 & 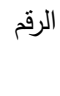 \\
\hline$\ldots 1$ & 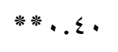 & لا أتناول الأدوية لمدة سنة كاملة & 1 \\
\hline$\ldots 1$ & $* * . .0$ & أفقد قواي العقلية & r \\
\hline$\ldots 1$ & $* * .0 r$ & أنترض للسجن & r \\
\hline$\ldots 1$ & $* \% * .07$ & أتعرض لحروق مشوهة & $\varepsilon$ \\
\hline$\ldots 1$ & $* * \ldots \wedge \wedge$ & أصاب بأحد الأمراض الوبائية & $\circ$ \\
\hline$\ldots$ & $* * \cdot . r V$ & لا أعاين الطبيب لمدة ه سنوات & T \\
\hline$\ldots 1$ & $* * \cdots+.7$ & أصاب بمرض عضال & $v$ \\
\hline$\ldots 1$ & 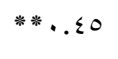 & لا أمرض طوال الثتاء & $\wedge$ \\
\hline$\ldots 1$ & $* * \ldots$ & أنجب ولدا معاقا & 9 \\
\hline$\ldots 1$ & $\% * . .00$ & أفقد معظم أفراد عائلتي في حادث & 1. \\
\hline$\ldots 1$ & $* \% * .07$ & أصاب بالعقم & 11 \\
\hline \multirow[t]{2}{*}{$\cdots 1$} & $* \%$..or & يتضاعف مدخولي الثهري كل ه & ir \\
\hline & & 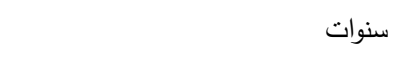 & \\
\hline$\ldots 1$ & $* * . .79$ & أصاب بالعمى & ir \\
\hline$\ldots 1$ & 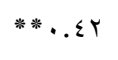 & أحظى بتقدير ومحبة كل الناس & $1 \varepsilon$ \\
\hline$\cdots 1$ & $* *$. or & أصاب بزيادة نسبة الكولسترول في الدم & 10 \\
\hline \multirow[t]{2}{*}{$\ldots 1$} & 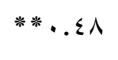 & لا أتعرض لمشاكل في الأسنان طيلة & 17 \\
\hline & & حياتي & \\
\hline$\ldots 1$ & $* * . . v 1$ & أجري عملية جراحية خطرة & iv \\
\hline$\ldots$ & $* * \cdot . v$. & أصاب بإلتهاب الكبد الفيروسي & 从 \\
\hline$\ldots \circ$ & $* . r \varepsilon$ & أتعرض لتسمح غذائي & 19 \\
\hline$\ldots$ & ***.. & أنا في مأمن من حوادث العمل & $r$. \\
\hline 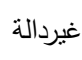 & .ro & أكون ضحية اختلاس & r \\
\hline$\ldots 1$ & $* * . .7 \varepsilon$ & يبتر جزء من جسمي & r \\
\hline \multirow[t]{2}{*}{$\ldots 1$} & $* \ldots$ & لا أصاب بأحد الأمراض المعدية طيلة & rr \\
\hline & & 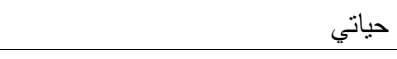 & \\
\hline
\end{tabular}

الخصائص السيكومترية لمقياس التدخين:

صدق المقياس: تم حساب صدق مقياس سلوك

التدخين بطريقتين هما:

صدق الاتساق الداخلي: حيث تم حساب معامل الارتباط الخطي كارل بيرسون Pearson بين بنود كل محور والدرجة الكلية على المقياس و النتائج فيما يلي:
التعريف الإجر ائي لمصطلحات الدراسة

تعريف التفاؤل غير الواقعي: هو اعتقاد الفرد

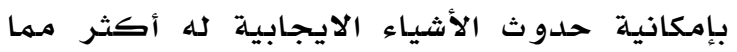
هي في الواقع، واعتقاده بعدم إمكانية حلدوث

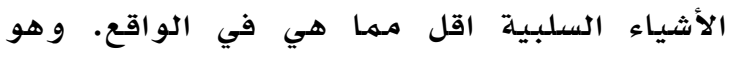

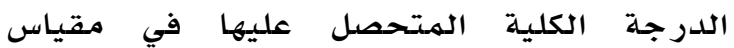

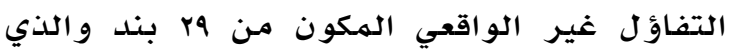

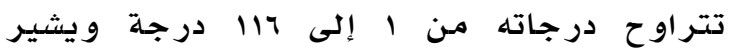
ارتفاع الدرجة إلى ارتفاع في التفاؤل غير لداته

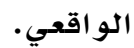

تعريف سلوك التدخين: هو سلوك استهلاك السجائر بانتظام. وهو الدرجة الكلية المتحصل

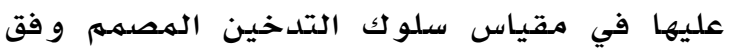
أربعة محاور يعبر كل محور على بعد من أبعاد

هذا السلوك، و تتراوح درجاته بين ·--•؛ درجة. تعريف سرطان الرئة: هو نمو فصيلة خلوية نمو سريع يفلت من التطور المنظم داخل الرئتين. الخصائص السيكو مترية لمقياس التفاؤل غير

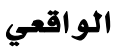
الصدق: تم حساب الصدق بطريقتين: صدق

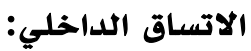

نلاحظ من جدول ا أن ^ץ بندا من 9r هي بنود

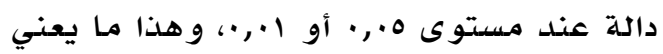
تمتع المقياس بدرجة عالية من الصدق. الصدق التمييزي: تم حساب الصدق التمييزي بحساب T-teste للدلالة على الفروق الموجودة المدئ

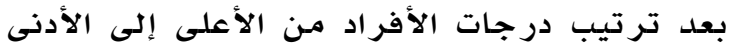

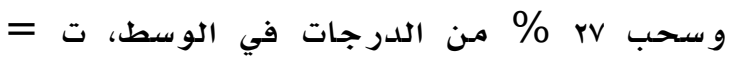

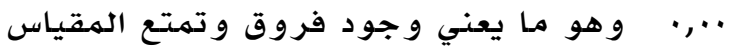
بالصدق التمييزي.

الثبات : تم حساب الثبات بثلاث طرق: حساب

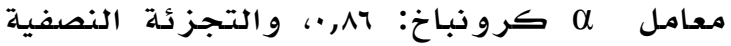

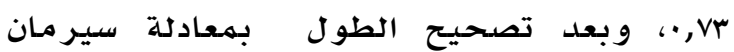

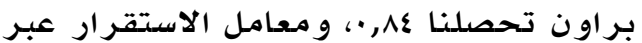
الزمن: معامل الارتباط = .ج,. لمدة بين 10-1N يوما، وهو ما يعني تمتع المقياس بلدرجة عالية

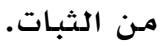


جدول ب

صدق الاتساق الداخلي لمقياس سلوك التخين

\begin{tabular}{|c|c|c|}
\hline 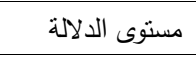 & 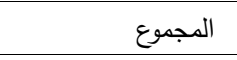 & 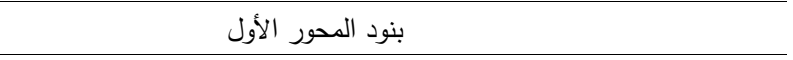 \\
\hline$\cdot, \cdot 1$ & 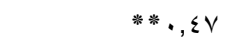 & 1-بدأت التخخين في سن اقل من V Vنة \\
\hline 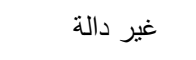 & .19 & r-تعلمت التدخين من رفاقي \\
\hline$\cdots+1$ & 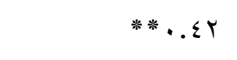 & 7-أدخن لأكون منل الآخرين \\
\hline$\ldots \circ$ & $* \cdot r 1$ & • 1-أدخن عندما أكون برفقة مدخنين آخرين \\
\hline$\ldots \circ$ & $* \cdot . r q$ & 7 ا 1 أدخن لأمنح نفسي منظرا لائقا \\
\hline$\ldots .0$ & *. & V V ا بداية سلوك التدخين جعلني أبدو ناضجا \\
\hline$\ldots \circ$ & $\because \cdot r \varepsilon$ & • . أدخن لأحصل على ثقة أكبر بنفسي \\
\hline$\ldots \circ$ & $* . r \varepsilon$ & r r-التنخين يجعلني مقبولا اجتماعيا \\
\hline$\cdots 1$ & $* * \ldots \vee V$ & ^ץ-حاولت النوقف عن سلوك التدخين قبل تعودي عليه \\
\hline$\cdots 1$ & *** $\cdot . \leqslant r$ & اب-التنخين يحسن علاقتي برفاقي \\
\hline 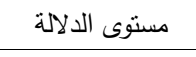 & 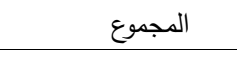 & 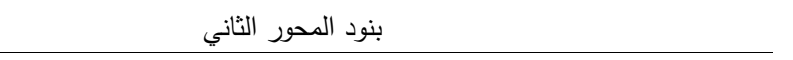 \\
\hline$\cdots 0$ & $* . r \varepsilon$ & 1-أدخن أول سيجارة عندما استيقظ من النوم \\
\hline$\cdots+1$ & $* * \ldots \varepsilon$ & V - V أدخن بصورة تلقائية دون تفكير \\
\hline$\cdots 0$ & 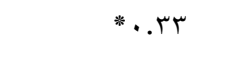 & 11-عندما لا أدخن لا أكون واعيا ولا استطيع التحكم في الرغبة في التخخين \\
\hline$\cdots \circ$ & $* \cdot r \wedge$ & 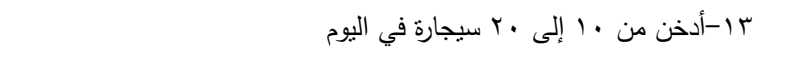 \\
\hline$\cdots+$ & 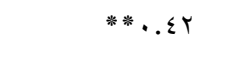 & ع ا-أدخن من · · إلى ·r سيجارة في اليوم \\
\hline$\cdots 0$ & $* .+q^{*}$ & 10-عندما لا أدخن لفترة تكون لدي رغبة في سيجارة لا استطيع مقاومتها \\
\hline$\cdots 1$ & 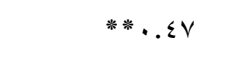 & ا ب-أدخن حتى في الأماكن الممنوع فيها ذلك \\
\hline$\cdots 1$ & $* * .0$ & مب-أدخن لأني تعودت على ذلك \\
\hline$\cdots 1$ & $\% * \cdot . \Sigma \vee$ & V r r-أدخن بشكل مستمر طوال اليوم \\
\hline$\cdots+1$ & $\% * . .00$ & rr-عندما لا املك سيجارة يجب أن أحصل عليها بكل الطرق \\
\hline 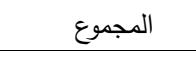 & 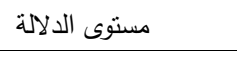 & 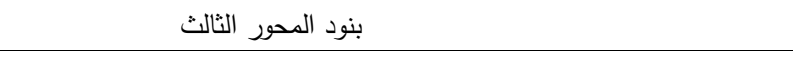 \\
\hline$\cdot, .0$ & $\because, r q$ & ع -اللذة في التدخين تبدأ مع الحركات التي أقوم بها لإشعال السيجارة \\
\hline 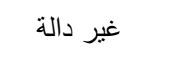 & $\cdot, r \cdot$ & ^-أدخن عندما أكون حزين \\
\hline$\cdot, \cdot+$ & $* * *_{\bullet}, \leqslant 0$ & r ا-أشعر باللذة عند إثعال أو إمساك سيجارة \\
\hline$\cdot, \cdot 0$ & $*, \Gamma \wedge$ & 9 1-عندما أكون هادئ تكون لاي رغبة في التخخين \\
\hline$\cdot, \cdot \cdot$ & $* *, 01$ & ؟ ؟-أدخن عندما أكون منوترا \\
\hline$\cdot, \cdot 1$ & $* *, 09$ & جr-التندخين يجعلني استرخي \\
\hline$\cdot, \cdot 1$ & $* \% \cdot$, or & سب-أحب تحريك السيجارة \\
\hline$\cdot, \cdot 1$ & $* *, 0 \leqslant$ & 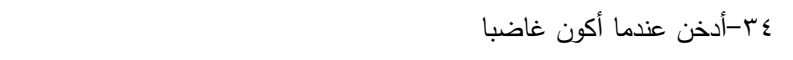 \\
\hline$\cdot, \cdot \cdot$ & $* * \cdot, 0 \leqslant$ & דr-سحب سيجارة يهدئني \\
\hline$\cdot, \cdot 1$ & $* *, 07$ & 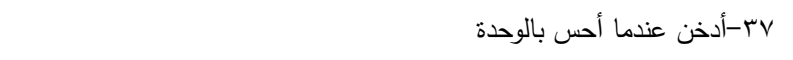 \\
\hline 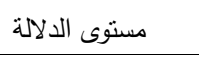 & 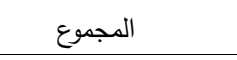 & 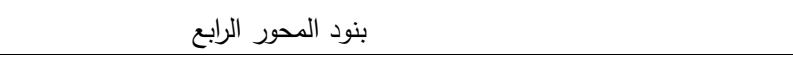 \\
\hline$\cdot, \cdot \cdot$ & $* * \cdot, \Sigma V$ & 1-عندما بدأت التدخين كنت اعلم أضراره على الصحة \\
\hline$\cdot, \cdot 1$ & $* *, \varepsilon r$ & 9-التذخين يسبب مرض الربو \\
\hline$\cdot, \cdot 0$ & $*, r q$ & 11 1-التخخين بسبب سرطان الرئة \\
\hline$\cdot, \cdot 1$ & $* *, 0$ & r r-التدخين يسبب اضطرابات في التتفس \\
\hline $.1-$ & $* *, \gamma r$ & 9ץ- التنخين يسبب سرطان الحنجرة \\
\hline$\cdot, \cdot 1$ & $\because *, V Y$ & • • التخخين يفقد الثهية للطعام \\
\hline$\cdot, \cdot 1$ & $* * \%, 79$ & هץ- التدخين بكثرة يزيد من احتمالات الوفاة \\
\hline$\cdot, \cdot 1$ & $* *, 0 \leqslant$ & ^ץ-حاولت التوقف عن التخخين عند معرفتي باضراره \\
\hline$\cdot, \cdot 1$ & $* * \%, 70$ & qج-التوقف عن التدخين يشعرني بالصداع \\
\hline$\cdot, \cdot 1$ & $* *, 0 \leqslant$ & • ـ -اعتقدت (اعتقد) أنني استطيع التوقف في الوقت المناسب قبل بداية المرض \\
\hline
\end{tabular}




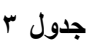

العلاقة بين التفاؤل غير الواقعي وعدد السجائر

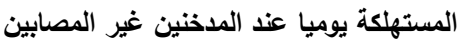

بسرطان الرئة

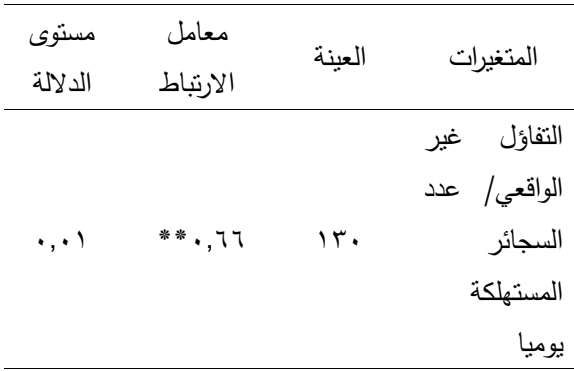

يتضح لنا من جدول r أن معامل الارتباط بين التفاؤل غير الواقعي وعدد السجائر المستهلكة

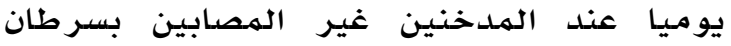
الرئة يساوي باج, ' وهو دال إحصائيا عند مستوى $\cdot, \cdot 1$

يتضح لنا مـن جلدول ع أن معامل الارتباط بين التفاؤل غير الواقعي وعدد سنوات تدخين السجائر يساوي - 01, • وهو دال الحول إحصائيا عند مستوى ا+,•، و أن معامل الارتباط بين التفاؤل غير الواقعي والسن عند المدلنين الهصنين

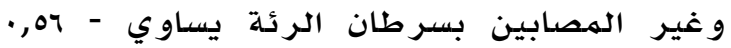
و هو دال إحصائيا عند مستوى ا.,.•.

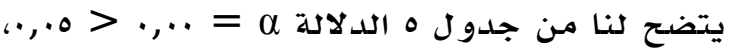
و هذا يعني وجود فروق، ونلاحظ من جدول

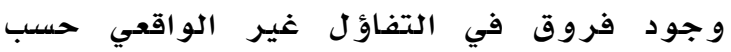
المستوى التعليمي لدى المداخنين غير المصدابين بسرطان الرئة وهي فروق دالة إحصائيا عند الدئئ

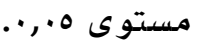

\section{جدول ؛}

العلاقة بين التفاؤل غير الواقعي وكل من عدد سنوات التلخين،

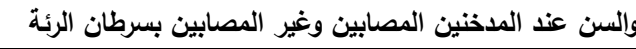

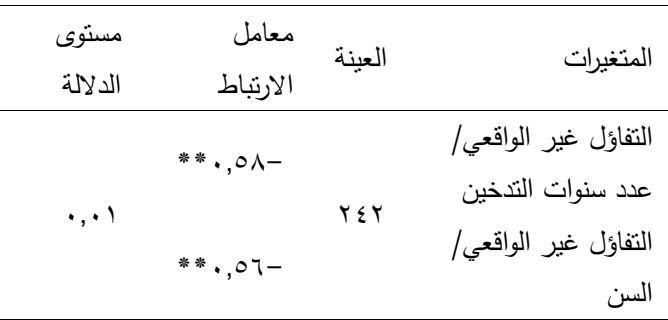

نلاحظ من جدول r أن رץ بند من •ع بند هي بنود دالة عند مستوى دلالة ه.,. أو ا.,. وهو مـا

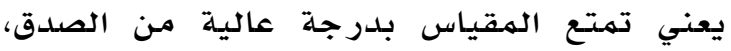
و أما البندين: rو ^ فغير دالين.

الهقارنة الطرفية (الصدق التمييزي): تم حساب الصدق التمييزي بحساب T Test للدلانة على الفروق التي كانت موجودة بعد ترتيب درجات

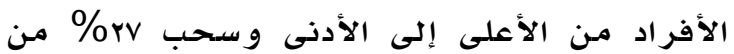

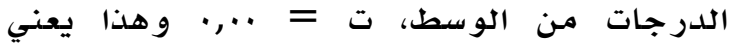
وجود فروق بين المجموعتين، اي قدرة مقياس سلوك التدخين على التمييز وبذانك فهودو يتمتع بلدرجة كبيرة مـن الصدق.

الثبات: تم حساب ثبات المقياس بثلاث طرق: معامل الاستقرار عبر الزمن: حيث يتم حساب

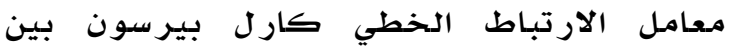
الدرجهة الكلية للقياس القبلي والقياس البعدي للهقياس له,، •، وحسـاب معامل الفا كرونباخ

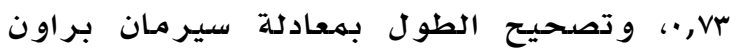

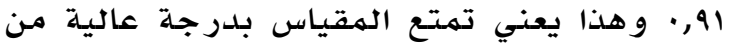
الثبات. الأساليب الإحصائية المستخدمـة: تم الاعتماد على (الع

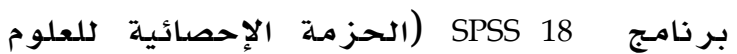

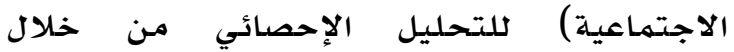

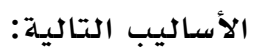

التكر ارات و النسب المئوية (في خصائص

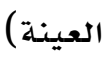

معامل الارتباط بيرسون

معامل ت للعينات المستقلة ) (- test التفاؤل غير الواقعي.

تحليل التباين (anova) لحسـاب الفروق

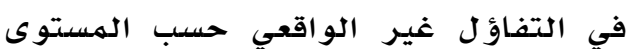
التعليمي.

\section{عرض ومناقشة نتائج الدراسة}

' • عرض النتائج: جاءت نتائج الدراسـة وفقا

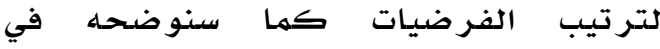
الجداول التالية: 
غير الواقعي بين المصابين وغير المصابين

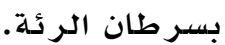

\section{مناقشة وتفسير النتائج}

فيما يلي مناقشة وتفسير نتائج الدراسة حسب تر تيب الفرضيات

الفرضية الأولى: تنص الفرضية الأولى على انه توجد علاقة ارتباطيه بين التفاؤل غير الواقعي و عدد السجائر المستهلكة يوميا عند المدارينين غير المصابين بسرطان الرئة. ومن أجل التحقق التقان من ذلك تم حساب معامل الارتباط بيرسون بين

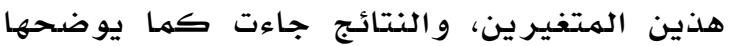

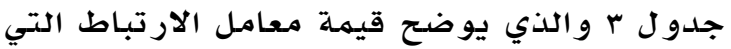
تساوي rا,· و هي قيمة دالة إحصائيا عند مستوى

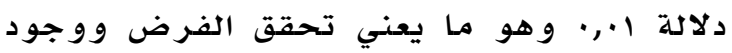

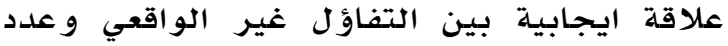
السجائر المستهلكة يوميا. إن هذه النتائج يمكن تفسيرها انطلاقا من أن التفاؤل غير الواقعي المرتفع يجعل تفكير الفرد الفرد

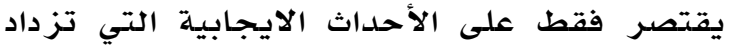
نسبة حدوثها بالنسبة إليه مقارنة بالآخرين بينما تقل نسبة حدوث الأشياء السلبية كالإصابة بالأمراض وهو ما يجعله يقبل على ممارسة سلوكيات الخطر والتي تتمثل حسب الفرضية في عدد السجائر المستهلكة يوميا وولوحظ من خلال تحليل النتائج ارتفاعها عند المدخنين غير المير

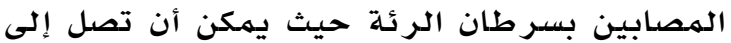

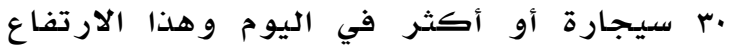
مرتبط بدرجة عالية من التفاؤل غير الواقعي.

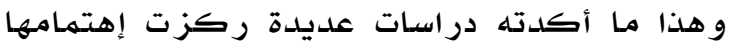
حول هذه العلاقة والتي نذكر من بينها دراسات كوبرن وبتر وواينستاين ( Cobrin \& Putter; (Mekenna, 1993; weinstein, 1980

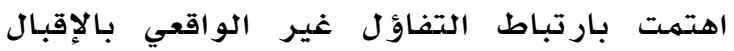
على ممارسة سلوك الخطر وقد أثبتت العلاقة الايجابية بينهما. الفرضية الثانية: تنص الفرضية الثانية على انه توجد علاقة ارتباطية بين التفاؤل غير الواقعي الفي الفية الفيانية وعدد سنوات تلدخين السجائر عند المدخنين

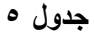
الفروق في التفاؤل غير الواقعي عند المدخنين غير المصابين بسرطان

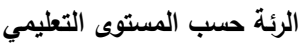

\begin{tabular}{|c|c|c|c|c|}
\hline مستوى الدلالة & & الدرجة & التعليمي & العينة \\
\hline غير دال & $\lambda, r \varepsilon$ & متوسط & & \\
\hline دال عند ه ., . & $10, \pi r$ & ثانوي & ابتدائي & \\
\hline دال عند ه.,. & * & جامعي & & \\
\hline غير دال & $\wedge, r \leqslant-$ & ابتدائي & & \\
\hline دال عند ه.,. & $* 7,9 \wedge$ & ثانوي & متوسط & \\
\hline دال عند ه.,. & FIr,Ar & جامعي & & \\
\hline دال عند ه .,. & $\begin{array}{r}- \\
* 10, r \\
\end{array}$ & ابتدائي & & $1 \pi$. \\
\hline دال عند .,. & $* \because, 9 \wedge-$ & منوسط & تانوي & \\
\hline غير دال & $\neg, \wedge \leq$ & جامعي & & \\
\hline دال عند $ه$.,. & 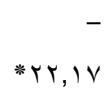 & ابتدائي & & \\
\hline دال عند ه.,. & $I r, \wedge r-$ & متوسط & جامعي & \\
\hline غير دال & $7, \wedge \leqslant-$ & ثانوي & & \\
\hline
\end{tabular}

العلاقة بين التفاؤل غير الواقعي وكل من التعود على سلوك التذخين،

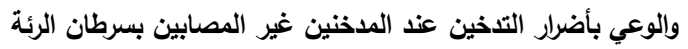

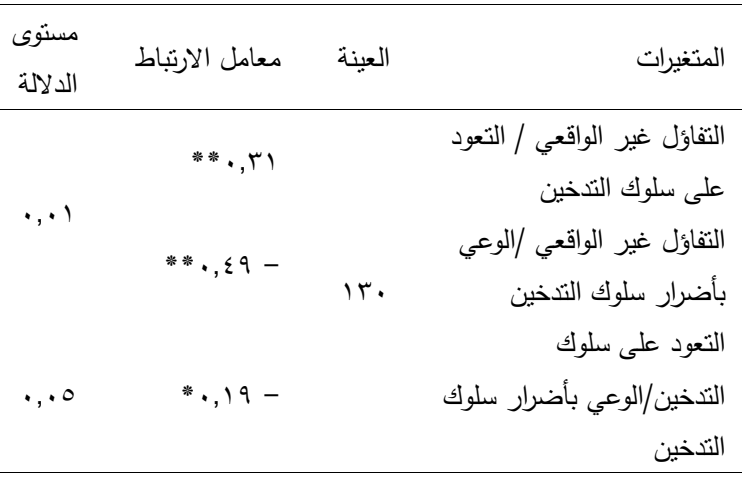

نلاحظ من جدول I أن معامل الارتباط بين

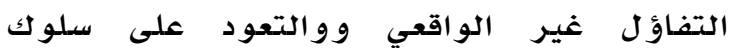
التدخين يساوي الr,· وهو دال إحصائيا عند مستوى 1.,•، و أن معامل الارتباط بين التفاؤل التال

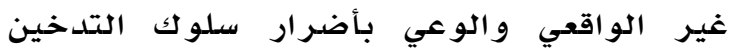

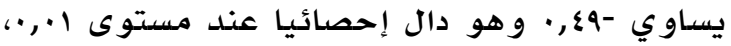

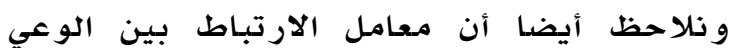

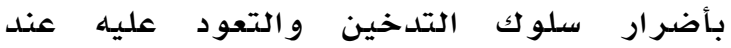

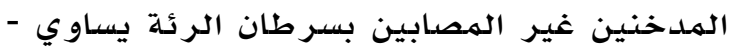
19,· وهو دال إحصائيا عند مستوى ه.,.. و قد الدين لوحظ كذلك فرق دال إحصائيا في التفاؤل 


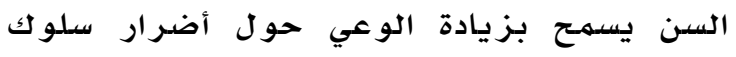

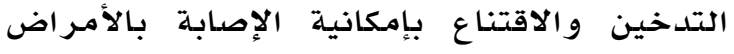

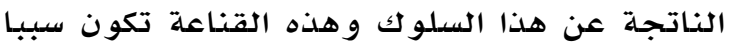
في انخفاض التفاؤل غير الواقعي، وهو ما يعكس التس التهل

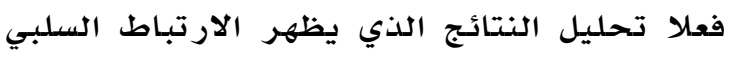
بين التفاؤل غير الواقعي والسن عند المداخنين

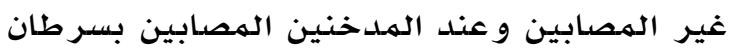

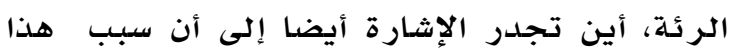

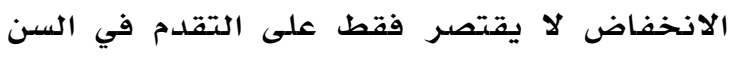
و ككن الإصابة بالهـرض في حد ذاتها قد تكون

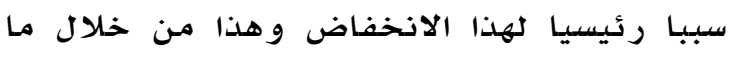

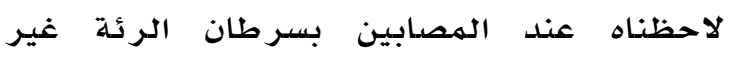
المتقدمين في السن.

إن نتائج هذه الدراسـة جاءت مطابقة لنتائج

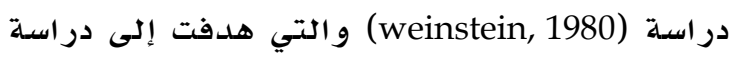

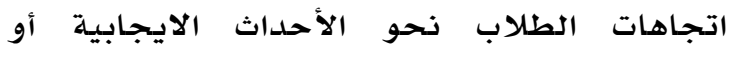

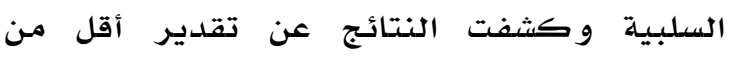

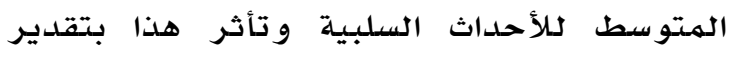

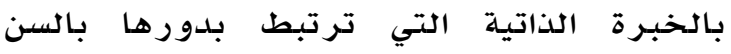
و التجارب الشخصية.

الفرضية الرابعة: تنص الفرضية الر ابعة على انه

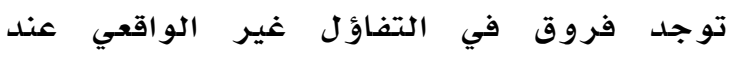

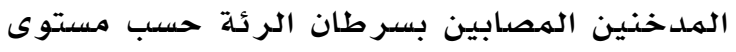

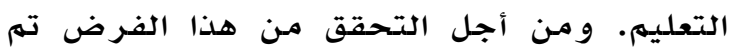
حساب الفروق بطريقة تحليل التباين (ANOVA) والنتائج جاءت كما يلي:

توجد فروق في التفاؤل غير الواقعي

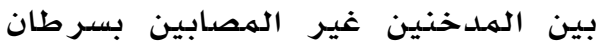
الرئة حسب مستوى التعليه.

توجد فروق في التفاؤل غير الواقعي

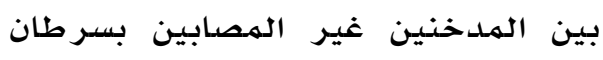

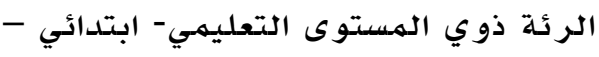
ثانوي لصالح مستوى التعليم الابتدائي. توجد فروق في التفاؤل غير الواقعي

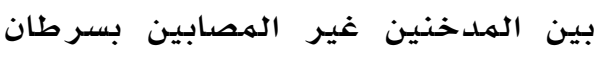

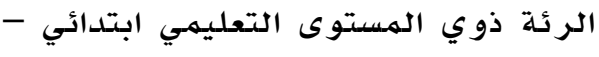
جامعي لصالح مستوى التعليه الابتدائي.
الهصدابين وغير الهصابين بسرطان الرئة. وومن أجل التحقق من هذا الفرض تهر حساب معامل الارتباط بيرسون بين هذين المتغيرين، والنتائج

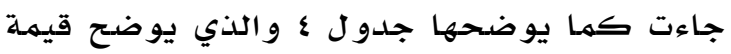

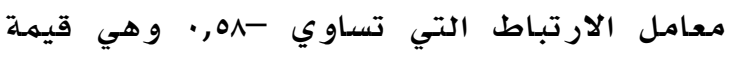

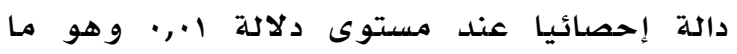
يعني تحقق الفرض ووجود علاقة سلبية بين

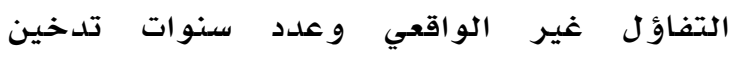
السجائر عند المدخنين المصابين وغير الهصابين

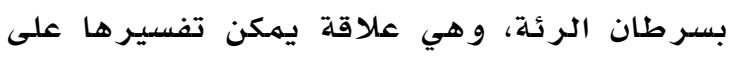

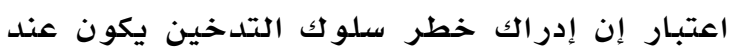

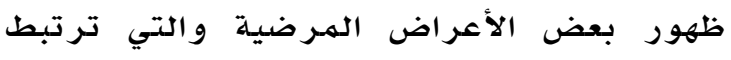

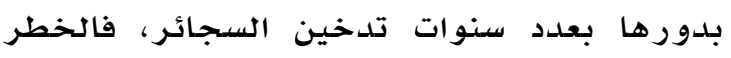

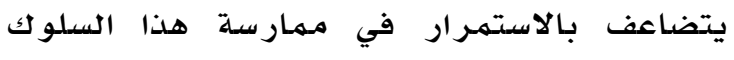

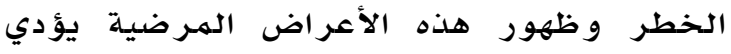
بالتأكيد إلى خفض التفاؤل غير الواقعي، وهو

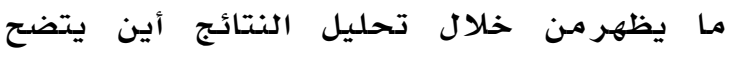
انخفاض في درجة التفاؤل غير الواقعي بزيادة

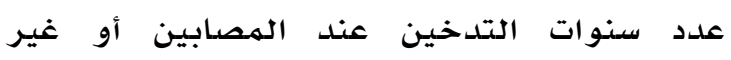

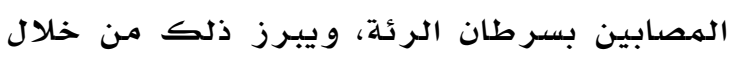

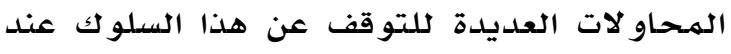

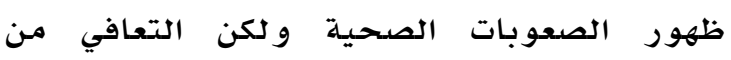
الاضطراب الصحي يؤدي الى رفع التفاؤل غير التون

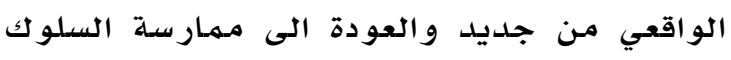
الخطر ولكن تبقى درجته في انخفاض مستهمر

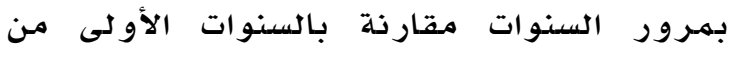
بداية سلوك التدخين، وتجدر الإثارة إلى أن هذا

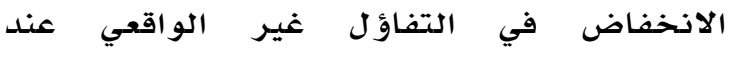

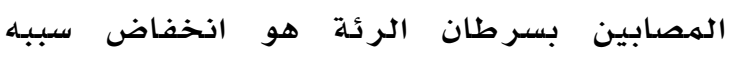
الرئيسي الإصابة بحد ذاتها بسر طان الرئة.

الفرضية الثالثة: تنص الفرضية الثالثة على أنه

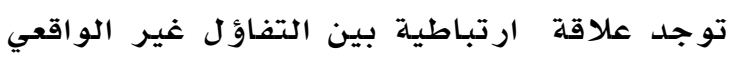
و السن عند الهصدابين وغير المصدابين بسرطان الرئة. و من أجل ذلك تم حسـاب معامل ارتباط بيرسون بين هذين المتغيرين، و النتائج موضحة النحل في جلدول ؛ الذي يعكس قيمس هينة المعامل التي

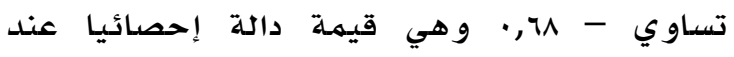
مستوى دلالة ا+, • و تعني تحقق الفر ضيلة ووجودود علاقة سلبية بين التفاؤل غير الواقعي والتقدم

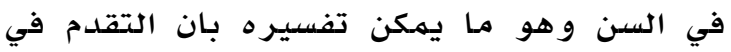


قيمة دالة عند مستوى دلالة ا+,• و وتعني تحقق الفرضية ووجود علاقة ايجابية بله بين التفاؤل

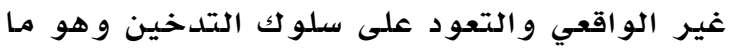

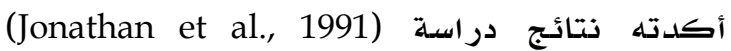
و التي تعتبر دراسـة مقار نة بين مـر اهقين مدخنين وغير المدخنين حيث أظهرت نتائجها و وجود إدراك عند المر اهقين الذين تعودوا على الاحتمـال سلوك التدخين واعتبروا احتمال إصابتهم بهذا

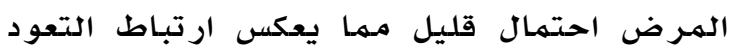
على هذا السلولك بارتفاع درة التفاؤل غير

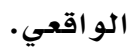
إن هذه النتائج يهكن تفسير ها انطلاقا مـن أن التعود على سلولك خطر وتحقيق بعض النتائج

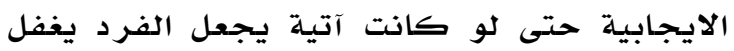
عن مخاطره ويمنـحه درجة عالية من التفاؤل

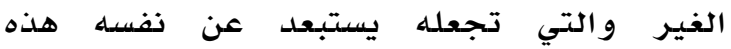
المخخاطر .

الفرضية السادسة: تص الفرضية السادسة على أنه توجد علاقة ارتباطية بين التفاؤل غير

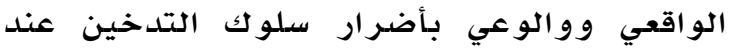

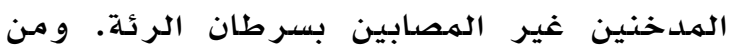
أجل ذلك من حساب معامل الارتباط بيرسون بين هذين المتغيرين والنتائج يوضحها جدول

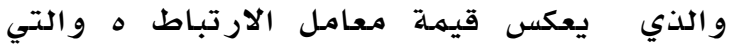
تساوي -ه؟§, و وهي قيمة دالة عند مستوى دلالة 1., و تعني وجود علاقة سلبية بين التفاؤل غير الوا اقعي و الوعي بأضر ار سلو كك التدخين. إن هذه

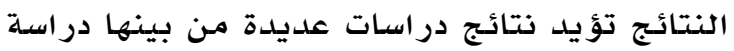

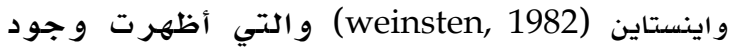
تفاؤل غير و اقعي مرتفع عند الطلاب فيها يتعلق

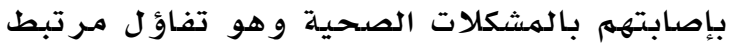
بـإمكانية التحكم في الهـرض، ونقص الخبرة

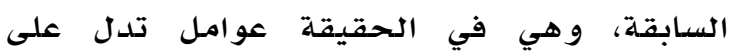
نقص الوعي الصحي الذي يؤدي إلى استبعاد

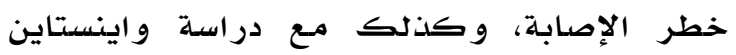
و آخرون (Weinstein et al., 2005) التي توصلت إلى وجود اعتقادات خاطئة لدى المدخنين حول أضرار سلوك التدخين و من بين هذه الاعتقادات إمكانية إنقاص التمارين الرياضية وتناول
لا توجد فروق في التفاؤل غير الواقعي

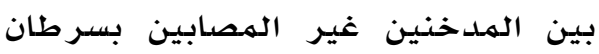
الرئة ذوي المستوى التعليمي ابتدائي متوسط توجد فروق في التفاؤل غير الواقعي

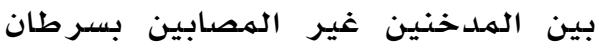
الرئة ذوي المستوى التعليمي متوسط المئ ثانوي لصالح مستوى التعليم المتوسط. توجد فروق في التفاؤل غير الواقعي

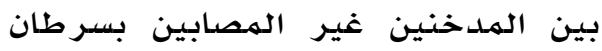
الرئة ذوي الهستوى التعليهي متوسطجامعي لصدالح مستوى التعليه المتوسط. توجد فروق في التفاؤل غير الواقعي

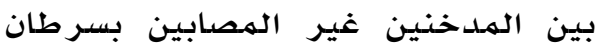
الرئة ذوي المستوى تعليمي ثانوي جامعي. إن هذه النتائج تعكس وجودا في التفاؤل غير

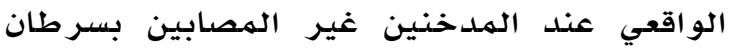
الرئة حسب مستوى التعليه. وهو ما ما يفسر الهير بالدور الفعال الذي يلعبه التعليهم في تنميـة الوعي بالأخطار و بالتالي خفض التفاؤل غير الواقعي ويظهر ذلك من خلال الاختلاف الواضح في الدرجات الهتحصل عليها في هذا المتغير

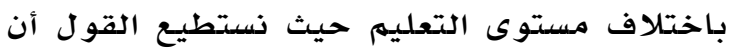
التفاؤل غير الواقعي يكون بدرجات مرتفعة إذا

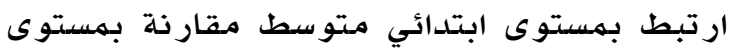

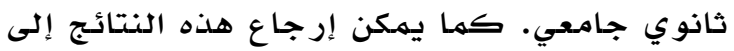

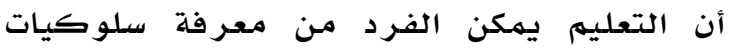
الخطر كما يمده بثقافة صحية تجعله يقدر لهرد بشكل صحيح مدى إمكانية تعرضه لـإِصابة

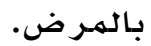

الفرضية الخامسة: تنص الفرضية الخامسة على

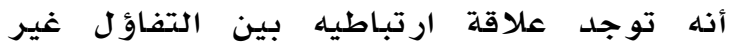

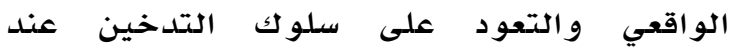

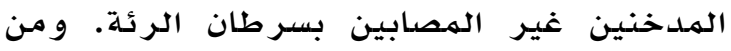
أجل التحقيق من هذه الفرضين الهيل ته حسـاب معامل الارتباط بيرسون و النتائج الموضدحة في جلدو ل 7 تعكس قيمة هذا الهعامل والتي تساوي الر,، وهي 
السلوك بتفاؤل غير واقعي مرتفع معتبرين أنفسههم بعيدين عن الإصلابة بأي مرض.

أما المصابون بسرطان الرئة فلاحظت الطالبة الباحثة انخفاض كبير في درجة التفاؤل غير

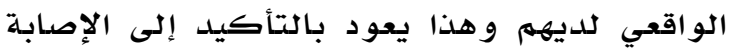

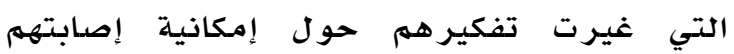
بالأحداث السلبية المختلفة مقارنة مـع الآخرين حيث أصبـحوا يقرون بهذه الإمكانية عكس غير

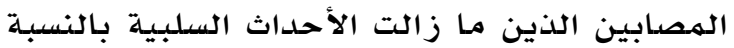
إليهم اقرب إلى غيرهم منهم.

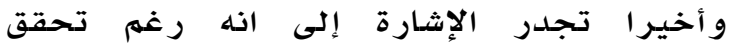

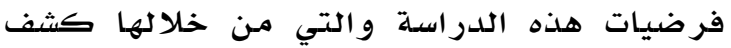
بعض الغموض عن متغير التفاؤل غير الواقعي هني إلا أنه تبقى هذه النتائج بحاجـة الى مزيد مـن

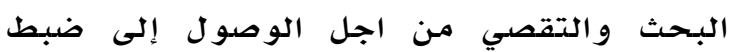

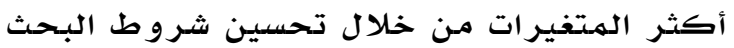
و استتخدام أدوات قياس أكثر دقة.

التوصيات

بعد النتائج التي تم التوصل اليها من خلال هذه

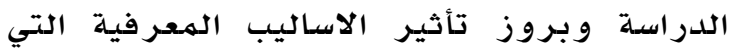
نتبناها في تحديدنا للاخطار و التي يمكن أن تكون خاطئة وتتسبب لنا في مشاكل صحيلة تتفاوت في درجة خطورتها و لكن يمكن أن تكون

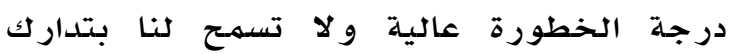
سلوكاتنا الخطرة لذلك نقتر ح ما يلي: ا اجراء دراسات معمقة حول متغير التفاؤل

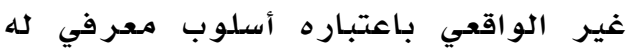
أثر بالغ و لكنه لم يحظ بالدر اسـة الكافية.

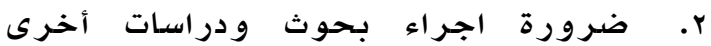
أكثر تعمقا حول متغير التفاؤل غير الو اقعي و علاقته بسلو كات الخطر . r. تصميهم برامـ علاجية للحد من سلوك التدخين اعتمادا على خفض التفاؤل غير الو اقعي. - الو

ع. اجراء دراسـات حول الاخطار الفعلية لسلو كك التدخين والتي من خلاء خلاكها يمكن نشر الوعي، لان ما تشير اليه الاحصائيات
الفيتامينات لهذه الأضرار ـهما أن الإصابة

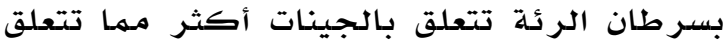

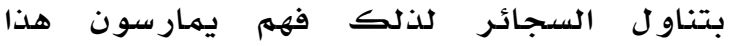

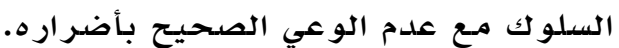

الفرضية السابعة: تنص الفرضية السابعة على أنه توجد علاقة ارتباطيه بين التعود على سلوك الك

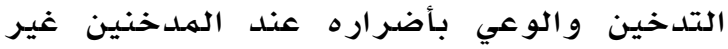

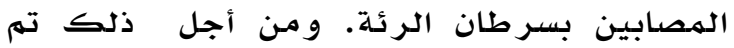
بحسـاب معامل الارتباط بيرسون بين المتغيرين و النتائج كما هي موضحة في جدول 1 و والذي

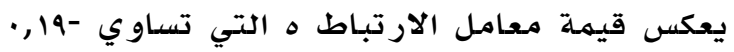
و هي قيمسة دالة عند مستوى دلالة ه., • وتعني

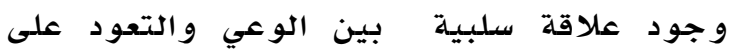
سلوك التدخين. إن هذه النتائج يمكن تفسيرها

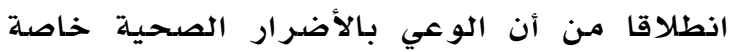
لسلوك التدخين يمكن أن يساهم في تخفيف

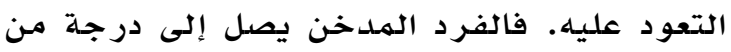

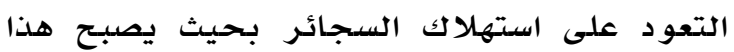
السلوك عادة يومية لا يستطيع الاستغناء عنها

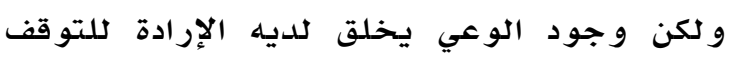

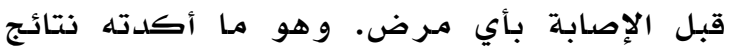

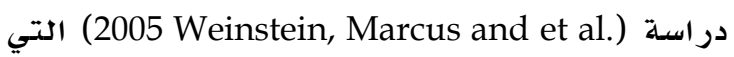
قارنت بين الهدخنين السابقين والذين تخلصوا من التعود على هذا السلولك والمدخنين الحاليين الذين ما زالوا تحت سيطرته و وعكست النتائج وجود فروق بين العينتين في الوعي بطريقة سلبية وتأثير هذا الأخير على التعود بطرين بـينة

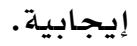

الفرضية الجزئية الثامنة: تنص الفرضية الثامنة على أنه توجد علاقة فروق في التفاؤل غير الواقعي بين المدخنين المصابين وغير الهصابين بسرطان الرئة. وومن أجل ذلك تهم حسـاب معامل الكل ت والذي اظهر وجود فروق بين العينتين حسب

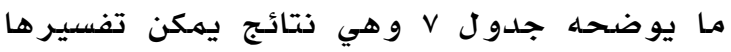
انطلاقا من أن التفاؤل غير الواقعي يكون مرتفعا

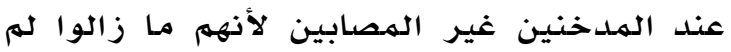

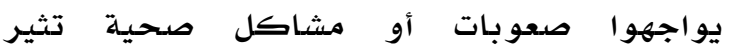
انتباههم إلى ما يمكن أن يسببـه السلوك ك الخطر الذي يمارسونه، لذا نجلدهم كما ظهر من خلإل الهال

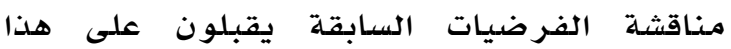


Chabrol, H., Niezborala, M., Chastan, E., Montastruc, J. L., \& Mullet, E. (2003). A study of the psychometric properties of the Fagestrom Test for Nicotine

Dependence. Addictive behaviors, 28(8), 1441-1445

Gilliard, J., \& Bruchon-Schweitzer, M. (2001). Development and validation of a multidimensional smoking behaviour questionnaire. Psychological reports,89(3), 499-509.

Jonathan, D. et al. (1991). Unrealistic optimism among adolescent smokers and non smokers. Journal of Primary Prevention, 11(3), 227-236.

Strecher, V. J., Kreuter, M. W., \& Kobrin, S. C. (1995). Do cigarette smokers have unrealistic perceptions of their heart attack, cancer, and stroke risks? Journal of Behavioral Medicine, 18(1), 45-54.

Mekenna. F. P. (1993). It won't happen to mé, unrealistic optimism or illusion of control. British journal of psychology.

Weinstein, N. D. (1980). Unrealistic optimism about future life events. Journal of Persnality and Social Psychology. 816.

Weinstein, N. D. (1982). Unrealistic optimism about susceptibility to health. Journal of Behavioral Medicine, 5(4), 441-460.

Weinstein, N. D., Marcus, S. E., \& Moser, R. P. (2005). Smokers' unrealistic optimism about their risk. Tobacco Control, 14(1), 5559.

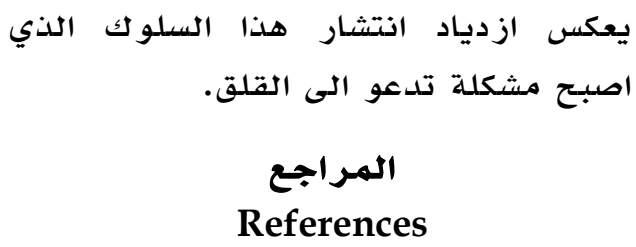

